\title{
Flame retardant and durable chloroprene rubber and styrene-butadiene rubber blends crosslinked with copper(I) oxide
}

\author{
Piotr Kobędza ${ }^{1}$ (D) Aleksandra Smejda-Krzewicka ${ }^{1} \cdot$ Anna Olejnik $^{1} \cdot$ Krzysztof Strzelec $^{1}$
}

Received: 20 December 2019 / Accepted: 14 October 2020 / Published online: 31 October 2020

(c) The Author(s) 2020

\begin{abstract}
The purpose of this work was to investigate the effect of application of copper(I) oxide $\left(\mathrm{Cu}_{2} \mathrm{O}\right)$ as an unconventional crosslinking agent of chloroprene (CR) and styrene-butadiene (SBR) rubber compositions. The use of $\mathrm{Cu}_{2} \mathrm{O}$ arises from the need to limit the application of $\mathrm{ZnO}$ as a CR crosslinking agent. The obtained results indicate that CR/SBR blends crosslinked with $\mathrm{Cu}_{2} \mathrm{O}$ are characterized by good mechanical properties and a high degree of crosslinking The results show that the proportion of both processing rubbers, as well as the amount of copper(I) oxide, influence the crosslinking of CR/SBR blends and the properties of the vulcanizates. Performing FTIR analysis has allowed the development of a crosslinking mechanism. Crosslinking presumably takes place according to the mechanism of Friedel-Crafts alkylation reaction. Silica, chalk, china clay and nanofiller (montmorillonite modified with quaternary ammonium salt containing hydroxyl groups) were applied as fillers. Among the fillers, silica had the greatest impact on improving the properties. It is arisen from silica activity, unlike other used fillers. The AFM analysis allowed us to determine the miscibility of the rubbers and dispersion of fillers. Thermal analysis was performed to determine the changes occurring as a result of material heating. The low intensity of the peaks corresponding to the crosslinking of the CR/SBR blends may indicate a small amount of bonds formed during heating, or possibility is the formation of connections between chains with a low binding energy. The use of chalk, china clay or silica increases the thermal stability of the vulcanizates. Obtained vulcanizates were characterized by increased incombustibility. The study of combustion time in the air showed that the prepared vulcanizates did not support the burning.
\end{abstract}

Keywords Copper(I) oxide $\cdot$ Chloroprene rubber $\cdot$ Styrene-butadiene rubber $\cdot$ Crosslinking $\cdot$ Flame retardant

\section{Introduction}

Chloroprene rubber (CR) is a material classified as a specialist elastomer. It results from its unique properties, namely good mechanical properties, resistance to technical media, susceptibility to crystallization, good adhesion and susceptibility to thermo crosslinking [1-3]. The greatest advantage of this elastomer is its increased flame resistance. This is related to the presence of chlorine atoms in the rubber main chain, which also influences the resistance to aging [4-6]. However, the use of CR in industry is limited and the chloroprene rubber is replaced by cheaper materials or elastomer compositions. Currently, the industry requires materials to

Piotr Kobędza

piotr.kobedza@dokt.p.lodz.pl

1 Faculty of Chemistry, Institute of Polymer and Dye Technology, Lodz University of Technology, Stefanowskiego 12/16, 90-924 Lodz, Poland be obtained at the lowest possible cost, while still having good product properties [7, 8]. In the elastomer technology, it is a common practice to use fillers, which reduces production costs and improves the mechanical properties of vulcanizates. Nevertheless, very often, classic materials are modified. One modification method is the incorporation of new types of crosslinking agents that have not been used before. Another modification method is the creation of elastomer blends [9].

The basis for the formation of elastomer blends is the creation of the network connecting elastomers macromolecules (Scheme 1). Reactions ensuing during the preparation of blends initially conduct to the branching of macromolecules and then their crosslinking. In the blends of two elastomers, reactions can take place between macromolecules in two ways: in one case, the bonds are formed between the chains of the same elastomer, in the second case, an interelastomer reaction occurs between macromolecules of two different elastomers and macromolecules 
Scheme 1 Interelastomer network made of A and B elastomer chains connected by $\mathrm{X}$ bridges

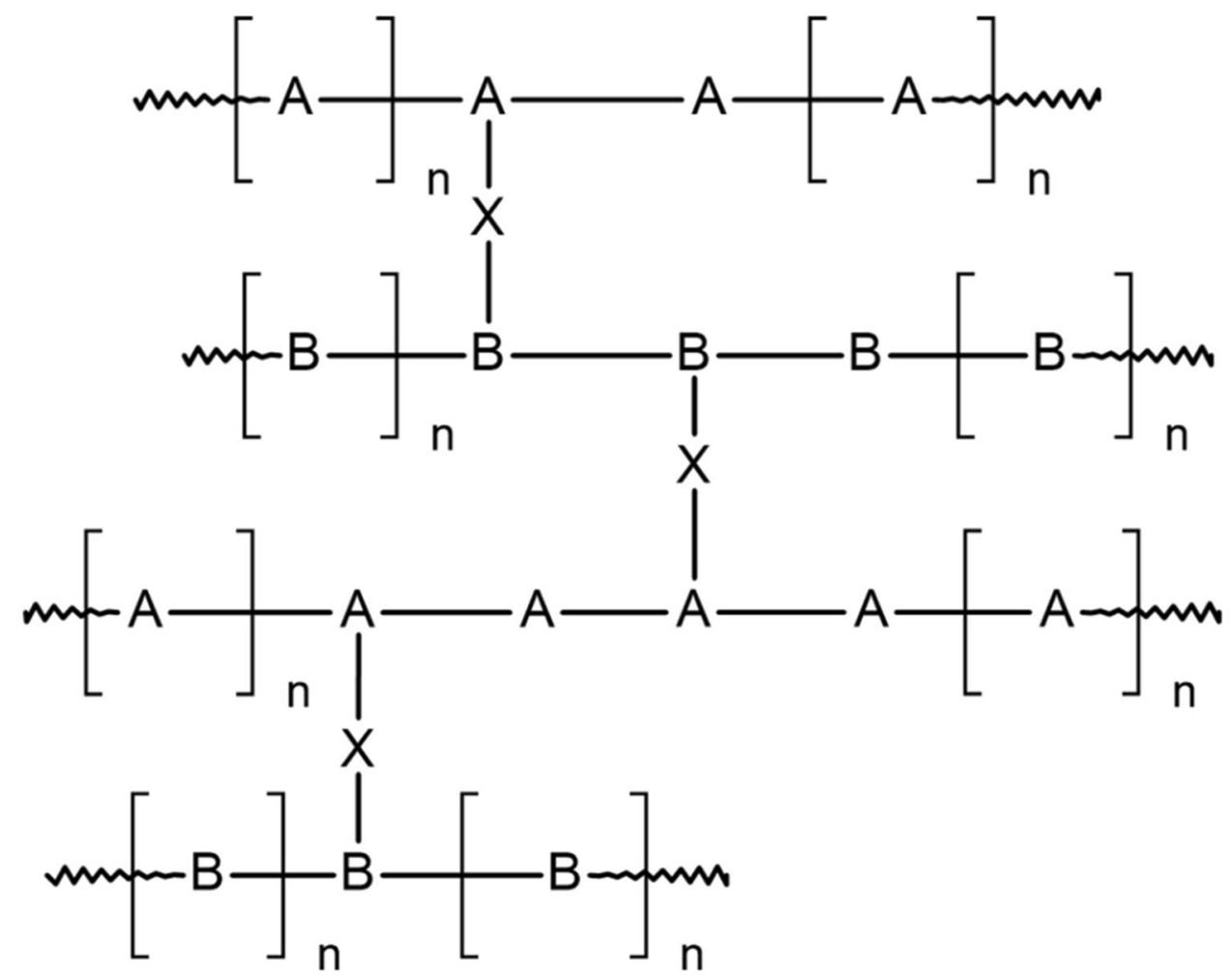

from one of the elastomers are grafted and bonded with macromolecules of the second elastomer [10].

The use of small molecular substances in elastomer compositions is a common method well described in the text. Such small molecular substances may interact with the elastomer matrix by participating in the formation of intramolecular bonds. An example of this type of interaction is the presence of small molecular substances serving as a crosslinking agent (e.g., sulfur and metal oxides) in an elastomer mix $[11,12]$. Also, it is possible that the small molecular substance does not participate in the formation of intramolecular bonds but instead assists reactions between the functional groups of the two elastomers, i.e., working as a catalyst [13-15]. A well-described example of a reaction without the participation of a small molecule substance is the reaction of chlorobutyl rubber (CIIR) with styrene-butadiene rubber (SBR) in the presence of a Lewis acid generated in situ. The mechanism of the reaction is based on the alkylation of styrene rings by the chlorine derived from the polyhalide catalyzed by the formed Lewis acid. For the creation of Lewis acid, it is necessary to incorporate a metal oxide, e.g. zinc oxide. The in situ generated aprotic Lewis acid, i.e. zinc chloride, is a catalyst for the reaction between the styrene rings and the other elastomer chains (in this example, CIIR macromolecules). The formation of bonds is also related to the inter-elastomer alkylation of the styrene rings containing 1,2-addition structural units $[16,17]$.
The purpose of this work was to use copper(I) oxide $\left(\mathrm{Cu}_{2} \mathrm{O}\right)$ as an unconventional crosslinking agent for new chloroprene and styrene-butadiene rubber blends (CR/ SBR). Seeking a substitute for $\mathrm{ZnO}$ as a crosslinking agent results from the restrictions on its use implemented by the European Union. As an alternative to $\mathrm{ZnO}$, different metal oxides can be used as a crosslinking agent $[18,19]$. The choice of $\mathrm{Cu}_{2} \mathrm{O}$ results from the ability of the crosslinking of $\mathrm{CR} / \mathrm{BR}$ mixes already described in the literature [20,21]. The advantage of using $\mathrm{Cu}_{2} \mathrm{O}$ is the smaller amount needed for crosslinking elastomer blends containing $\mathrm{CR}$ compared to other crosslinkers. Additionally, the application of $\mathrm{Cu}_{2} \mathrm{O}$ serves as both a crosslinking agent and an electron acceptor. A smaller amount of used materials reduces the costs of making the composition.

\section{Experimental}

\section{Materials}

In this work, two types of elastomers were used: chloroprene rubber (CR) (Baypren ${ }^{\circledR} 216 \mathrm{MV}$ from Lanxess $\mathrm{GmbH}$, Germany) with a density of $1.23 \mathrm{~g} / \mathrm{cm}^{3}$ and Mooney viscosity (ML $1+4100{ }^{\circ} \mathrm{C}$ ) of $43 \pm 5$, and styrene-butadiene rubber (SBR) $\left(\mathrm{KER}^{\circledR} 1502\right.$ from Synthos S.A.) with Mooney viscosity (ML $1+4100{ }^{\circ} \mathrm{C}$ ) of $50 \pm 5$ and bonded styrene of $23.5 \pm 1.5 \%$ (by weight). Copper(I) 
oxide $\left(\mathrm{Cu}_{2} \mathrm{O}\right)$ (POCH S.A., Poland) with a density of $6 \mathrm{~g} /$ $\mathrm{cm}^{3}$ and purity $>99 \%$ was used as a crosslinking agent. Stearic acid (Chemical Worldwide Business Sp. z o.o., Poland) with a density of $0.85 \mathrm{~g} / \mathrm{cm}^{3}$ was used as a dispersing agent.

The fillers used for elastomer blends were as follows:

- Fumed silica (Aerosil A380 from Evonik Industries AG), with an average primary particle size of $7 \mathrm{~nm}$, a surface area of $380 \mathrm{~m}^{2} / \mathrm{g}$ and a density of $2.2 \mathrm{~g} / \mathrm{cm}^{3}$,

- Technical chalk, a product of Pharma Cosmetics, with a density of $2.93 \mathrm{~g} / \mathrm{cm}^{3}$ and grain size $<10 \mu \mathrm{m}(99.7 \%)$,

- Technical china clay (POCH S.A., Poland) with a density of $2.6 \mathrm{~g} / \mathrm{cm}^{3}$ and average grain size $1.3 \mu \mathrm{m}$,

- Nanofiller NanoBent ZS1 (ZGM "Zebiec", Poland), montmorillonite modified by an ammonium salt-containing hydroxyl groups, with an average grain size $20-60 \mu \mathrm{m}(81 \%), \leq 20 \mu \mathrm{m}(19 \%)$ and a layer spacing $3.8-3.9 \mathrm{~nm}$.

Silica, chalk and china clay were used in an amount of $30 \mathrm{phr}$, while the nanofiller was used in an amount of $5 \mathrm{phr}$. The fillers were incorporated in the preparation of blends using a laboratory roll mill. The fillers were used to change the properties of the vulcanizates and to reduce the composition preparation costs.

\section{Research methods}

The elastomer blends were prepared using a Krupp-Grusan laboratory two-roll mill with a roll diameter of $200 \mathrm{~mm}$ and a length of $450 \mathrm{~mm}$. The temperature of the roll was $20-25{ }^{\circ} \mathrm{C}$, while the speed of the front roll was $200 \mathrm{rpm}$, with the rolls friction of 1:1.25. The preparation of one blend lasted $10 \mathrm{~min}$ and then the samples were conditioned for $24 \mathrm{~h}$.

Vulcametric measurements were determined by the "WG02 " rheometer with an oscillating rotor, heated to $160{ }^{\circ} \mathrm{C}$. The oscillation frequency of the rotor was $1.7 \pm 0.1 \mathrm{~Hz}$. The test took $60 \mathrm{~min}$ and performed according to PN-ISO 3417:2015-12.

The determination of equilibrium volume swelling was performed. Vulcanizates samples were cut in four different shapes. Each of them weighed $25-50 \mathrm{mg}$, with an accuracy of $0.1 \mathrm{mg}$. Then, samples were placed into solvents: toluene or heptane, using a weighing bottle. The prepared samples were placed in a thermostatic chamber for $72 \mathrm{~h}$ at $25 \pm 1^{\circ} \mathrm{C}$, which after this time were bathed with diethyl ether, dried on filter paper, and then weighed again. Then the samples were dried in a dryer at a temperature of $50^{\circ} \mathrm{C}$ to a constant weight and they were reweighed. The equilibrium volume swelling $\left(Q_{\mathrm{V}}\right)$ was calculated from Eq. 1:
$Q_{\mathrm{V}}=Q_{\mathrm{W}} \cdot \frac{d_{\mathrm{v}}}{d_{\mathrm{s}}}$

where, $Q_{\mathrm{W}}$ is the equilibrium weight swelling $(\mathrm{mg} / \mathrm{mg}), d_{\mathrm{v}}$ is the vulcanizate density $\left(\mathrm{g} / \mathrm{cm}^{3}\right)$ and $d_{\mathrm{s}}$ is solvent density $\left(\mathrm{g} / \mathrm{cm}^{3}\right)$.

The equilibrium weight swelling was calculated from Eq. 2:

$Q_{\mathrm{w}}=\frac{m_{\mathrm{s}}-m_{\mathrm{d}}}{m_{\mathrm{d}}^{*}}$

where, $m_{\mathrm{s}}$ is the swollen sample weight $(\mathrm{mg}), m_{\mathrm{d}}$ is the dry sample weight $(\mathrm{mg})$ and $m_{\mathrm{d}} *$ the reduced sample weight (mg).

The reduced sample weight was calculated from Eq. 3:

$m_{\mathrm{d}}^{*}=m_{\mathrm{d}}-m_{0} \cdot \frac{m_{\mathrm{m}}}{m_{\mathrm{t}}}$

where, $m_{0}$ is the initial sample weight $(\mathrm{mg}), m_{\mathrm{m}}$ is the mineral content in the blend $(\mathrm{mg})$ and $m_{\mathrm{t}}$ is the total weight of the blend (mg).

The bonding degree of styrene-butadiene rubber on chloroprene rubber $\left(X_{\mathrm{SBR}}\right)$ was calculated from Eq. 4 :

$X_{\mathrm{SBR}}=\left(\frac{W_{\mathrm{QT}}-W_{\mathrm{QE}}}{W_{\mathrm{QT}}}\right)$

where: $W_{\mathrm{QT}}$ is the theoretical leachability and $W_{\mathrm{QE}}$ is experimental leachability.

The theoretical leachability is calculated from Eq. 5:

$W_{\mathrm{QT}}=\left(V_{\mathrm{SBR}} * E_{\mathrm{SBR}}\right)+\left(V_{\mathrm{CR}} * E_{\mathrm{CR}}\right)$

where, $V_{\mathrm{SBR}}$ and $V_{\mathrm{CR}}$ are the mass fractions of SBR and CR, respectively and $E_{\mathrm{SBR}}$ and $E_{\mathrm{CR}}$ are the theoretical leachability of SBR and CR, respectively.

The experimental leachability is calculated from Eq. 6 . The masses used for the $W_{\mathrm{QE}}$ calculations were obtained during the measurements of the equilibrium volume swelling:

$W_{\mathrm{QE}}=\frac{m_{0}-m_{\mathrm{d}}}{m_{\mathrm{d}}^{*}}$.

Determination of Mooney-Rivlin elasticity constants $\left(2 C_{1}\right.$ and $\left.2 C_{2}\right)$ was performed. The elasticity constants were calculated on the basis of the Mooney-Rivlin equation (Eq. 7):

$\frac{P}{2 A_{0} \cdot\left(\lambda-\lambda^{-2}\right)}=2 C_{1}+2 C_{2} \cdot \lambda^{-1}$

where, $P$ is the deformation force at $\lambda(\mathrm{kg}), \lambda$ is the deformation $\left(\lambda=l / l_{0}\right), l$ is the measuring section of the sample loaded with $P(\mathrm{~cm}), l_{0}$ is the measuring section of the unloaded 
sample $(\mathrm{cm}), A_{0}$ is the cross-sectional area of the unloaded sample $\left(\mathrm{cm}^{2}\right), 2 C_{1}$ is the first elasticity constant $\left(\mathrm{kg} / \mathrm{cm}^{2}\right)$ and the $2 C_{2}$ is the second elasticity constant $\left(\mathrm{kg} / \mathrm{cm}^{2}\right)$.

Extraction of vulcanizates in the boiling acetone or heptane vapors in a Soxhlet apparatus for $48 \mathrm{~h}$ was performed. After the given time, the samples were dried to a constant weight in a vacuum oven at $50{ }^{\circ} \mathrm{C}$. Results of the extraction allowed to determine the content of non-rubber substances.

Mechanical properties including stress-at-elongation 100, $200,300 \%\left(\mathrm{~S}_{\mathrm{e} 100}, \mathrm{~S}_{\mathrm{e} 200}, \mathrm{~S}_{\mathrm{e} 300}\right)$, tensile strength $\left(\mathrm{TS}_{\mathrm{b}}\right)$ and elongation-at-break $\left(E_{\mathrm{b}}\right)$ were tested by the universal testing machine ZwickRoell 1435. The test was performed according to PN-ISO 37:2007.

Infrared spectra were made using the FTIR-ATR method and recorded using a Bio-Rad 175 spectrometer. Samples for infrared tests were prepared from elastomer blends before and after their crosslinking.

The surface morphology of the vulcanizates was examined using the atomic force microscopy (AFM) in tapping mode branded by Metrology Series 2000 and produced by Molecular Imaging. AFM images were analyzed with a procedure developed by Horcas et al. [22].

Flammability of the vulcanizates was determined using the oxygen index (OI) method. Vulcanizate samples of $50 \times 10 \times 4 \mathrm{~mm}$ were placed vertically in the holder and covered with a quartz column. The construction of the apparatus is protected by the Polish patent [23]. Inside the column, the sample was perfused with a mixture of oxygen $\left(\mathrm{O}_{2}\right)$ and nitrogen $\left(\mathrm{N}_{2}\right)$. The gas flow rate was determined by rotameters. The nitrogen flow was constant and amounted to $400 \mathrm{~L} / \mathrm{h}$, while the oxygen flow was variable and selected to determine the lowest oxygen concentration in the gas mixture at which the sample burned during $180 \pm 15 \mathrm{~s}$. The samples were ignited for $5 \mathrm{~s}$ with a gas burner. After the removal of the fire source, the time of their combustion was measured. The test was performed according to PN-ISO 4589-2. The oxygen index (OI) was calculated from Eq. 8:

$\mathrm{OI}=\frac{\mathrm{O}_{2}}{\mathrm{O}_{2}+\mathrm{N}_{2}}$

where, $\mathrm{O}_{2}$ is the oxygen flow rate $(\mathrm{L} / \mathrm{h})$ and $\mathrm{N}_{2}$ is the nitrogen flow rate $(\mathrm{L} / \mathrm{h})$.

Thermal analysis (TGA, DTG and DSC) was performed using a Mettler Toledo TGA/DSC1 device. TGA and DTG analyses were performed using two-step procedure. First, samples of vulcanizates were heated in the temperature range of $25-600{ }^{\circ} \mathrm{C}$ in an argon atmosphere (flow rate $50 \mathrm{~mL} / \mathrm{min}$ ), with a heating rate of $20^{\circ} \mathrm{C} / \mathrm{min}$. Next, the gas was changed into the air (flow rate $50 \mathrm{~mL} / \mathrm{min}$ ) and heating was continued up to $900{ }^{\circ} \mathrm{C}$ with the same heating rate. DSC measurements were performed on rubber blends. Samples were heated from -100 to $250{ }^{\circ} \mathrm{C}$, with a heating rate of
$10{ }^{\circ} \mathrm{C} / \mathrm{min}$. Nitrogen $(80 \mathrm{~mL} / \mathrm{min})$ was used as the protective gas, whereas liquid nitrogen was applied to cool the sample before the measurement.

\section{Results and discussion}

\section{CR/SBR blend crosslinking degree and its effect on vulcanizates properties}

To investigate the effect of copper(I) oxide $\left(\mathrm{Cu}_{2} \mathrm{O}\right)$ as an unconventional crosslinking agent, blends of chloroprene rubber and styrene-butadiene rubber (CR/SBR) were prepared. Elastomers were used in varying proportions: 80/20, 60/40, 40/60 and 20/80 (by weight), respectively. Additionally, for comparison, mixes containing only CR or SBR (marked as 100/0 and 0/100, respectively) were prepared. $\mathrm{Cu}_{2} \mathrm{O}$ was used in an amount of four weight parts of $\mathrm{Cu}_{2} \mathrm{O} / 100$ weight parts of rubbers $(4 \mathrm{phr})$.

The results of the vulcametric measurements are shown in Fig. 1. The scorch time $\left(t_{02}\right)$ of the tested blends was comparable and equal to 2 and $0.5-3 \mathrm{~min}$. This is an indication of a similar safe blend processing, regardless of the proportional rubbers used. The optimum vulcanization time $\left(t_{90}\right)$ was determined for blends containing $\geq 40$ weight parts of CR. For a mix containing 100 weight parts of chloroprene rubber $t_{90}$ was equal to $42.6 \mathrm{~min}$. With increasing SBR content in the blends, the vulcanization time was decreased to the smallest value $\left(t_{02}=13.9 \mathrm{~min}\right)$ for the CR/SBR $(40 / 60$ by wt) blend. The minimum torque $\left(M_{\min }\right)$ value for all CR/SBR blends as well as for mixes containing CR and SBR separately was comparable and ranged from 10-14 $\mathrm{dNm}$. These results indicate that all the prepared blends had similar viscosity. Torque increased after $30 \mathrm{~min}$ of the heating $\left(\Delta M_{30}\right)$ of chloroprene and styrene-butadiene rubbers blend in the amount of 80 and 20 weight parts (CR/SBR at 80/20) was the largest and equal to $31.9 \mathrm{dNm}$. A decreasing amount of $\mathrm{CR}$ in the blend resulted in slower torque growth, having the value of $4.4 \mathrm{dNm}$ for CR/SBR at 20/80 (by weight) blend. By comparison, torque increase after $30 \mathrm{~min}$ of heating for the CR mix was equal to $25.4 \mathrm{dNm}$ and for the SBR mix $\Delta M_{30}$ was equal to $0.6 \mathrm{dNm}$. The obtained results indicate that a larger amount of chloroprene rubber in the CR/SBR blend improves the torque increase of the system and the copper(I) oxide reacts mainly with the chloroprene rubber. This is evidenced by the highest value of torque increase after $30 \mathrm{~min}$ of heating for the CR/SBR ( $80 / 20$ by weight) blend. Simultaneously, other parameters $\left(t_{02}, t_{90}, M_{\min }\right)$ achieved similar values in blends containing different proportional rubbers. Additionally, the presence of SBR in the blends causes the appearance of a vulcanization plateau, which is positive, particularly in terms of technology. The obtained results show the greatest amount of interactions 


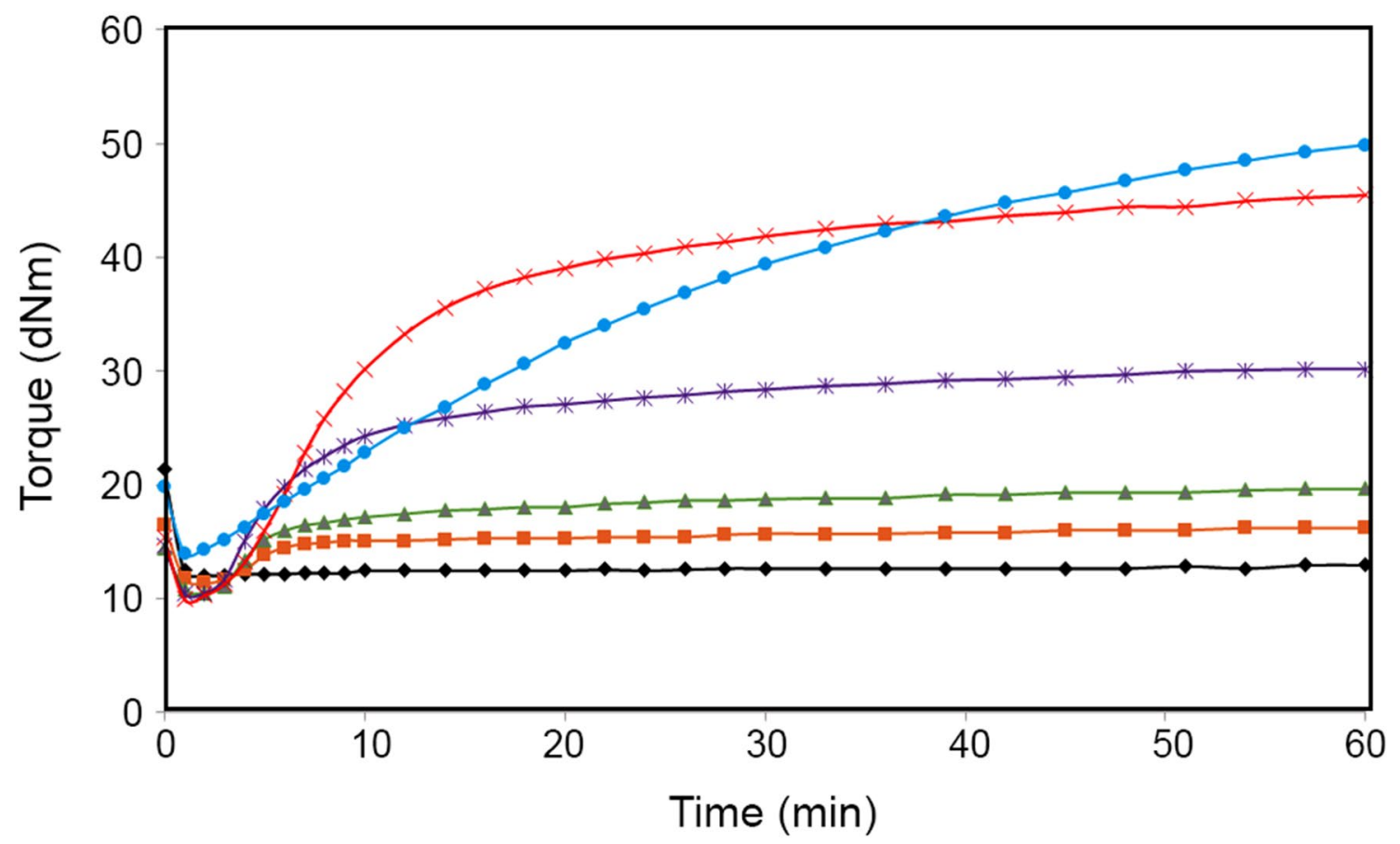

Fig. 1 Vulcametric kinetics of chloroprene and styrene-butadiene rubbers (CR/SBR) blends crosslinked with copper(I) oxide (4 phr of $\mathrm{Cu}_{2} \mathrm{O}$ ); where: diamond lined $0 / 100 \mathrm{CR} / \mathrm{SBR}$, orange squared line

20/80 CR/SBR, green triangle line 40/60 CR/SBR, purple asterisk line $60 / 40 \mathrm{CR} / \mathrm{SBR}$, red times line $80 / 20 \mathrm{CR} / \mathrm{SBR}$, blue circle line $100 / 0 \mathrm{CR} / \mathrm{SBR}$

which are formed during the heating of 80 weight parts of $\mathrm{CR}$ and 20 weight parts of SBR. The main advantage of CR/ SBR at $80 / 20$ (by weight) blend, relative to the CR mix, is the presence of a vulcanization plateau, which shortens the time needed to crosslink the blend. Also, a larger increase in torque after $30 \mathrm{~min}$ of the heating $\left(\Delta M_{30}=31.9 \mathrm{dNm}\right.$ for $\mathrm{CR} /$ $\operatorname{SBR}\left(80 / 20 \mathrm{phr}\right.$ ) blend and $\Delta M_{30}=25.4 \mathrm{dNm}$ for CR mix) is beneficial considering the processing of this material.

The relationship between the crosslinking degree and the proportion of rubbers in the blends was confirmed by the results of the equilibrium volume swelling in toluene $\left(Q_{\mathrm{V}}^{\mathrm{T}}\right)$. For the CR/SBR at 80/20 (by weight) vulcanizate, the value of $Q_{\mathrm{V}}^{\mathrm{T}}$ was equal to $6.85 \mathrm{~cm}^{3} / \mathrm{cm}^{3}$, while for the $\mathrm{CR} / \mathrm{SBR}$ at 20/80 (by weight) vulcanizate $Q_{\mathrm{V}}^{\mathrm{T}}$ was equal to $16.86 \mathrm{~cm}^{3} /$ $\mathrm{cm}^{3}$ (Table 1). For the CR vulcanizate, the equilibrium volume swelling in toluene was the smallest $\left(Q_{\mathrm{V}}^{\mathrm{T}}=5.28 \mathrm{~cm}^{3} /\right.$ $\mathrm{cm}^{3}$ ). It follows that with the increase of CR content in the vulcanizate the value of equilibrium volume swelling in toluene decreases. In turn, SBR samples were dissolved. This indicates the lack of crosslinking of this rubber with $\mathrm{Cu}_{2} \mathrm{O}$. A small value of the equilibrium volume swelling indicates a large number of bonds formed. This value can be related to the crosslinking degree. CR/SBR at $80 / 20$ (by weight) vulcanizate achieved the lowest $Q_{\mathrm{V}}^{\mathrm{T}}$ value among other CR/ SBR vulcanizates. A similar relationship can be observed for samples subjected to equilibrium swelling in heptane. The highest value was obtained for CR/SBR at 20/80 (by weight)

vulcanizate $\left(Q_{\mathrm{V}}^{\mathrm{H}}=4.86 \mathrm{~cm}^{3} / \mathrm{cm}^{3}\right)$. Whereas the lowest value of equilibrium swelling in heptane was obtained for the CR vulcanizate $\left(Q_{\mathrm{V}}^{\mathrm{H}}=0.51 \mathrm{~cm}^{3} / \mathrm{cm}^{3}\right)$. This value indicates the $\mathrm{CR}$ resistance to heptane; the polar rubber is insoluble in the non-polar solvent. It is possible that the $\mathrm{CR}$ has not been completely crosslinked with $\mathrm{Cu}_{2} \mathrm{O}$ and partially it has been washed out by the solvent. The opposite is with non-polar SBR, which dissolves in heptane. The swelling results illustrate this relationship; along with the increasing SBR content in the composition, the $\mathrm{Q}_{\mathrm{V}}$ value also increases.

The bounding degree of SBR with CR allows to determine that what part of the styrene-butadiene rubber remains in the vulcanizate after treatment with a non-polar solvent (heptane). Simultaneously, this may be an information on the amount of SBR that is involved in the formation of interlastomeric bonds with CR. For CR/SBR at $80 / 20$ (by weight) vulcanizate, the amount of bounded SBR is $95 \%$ (Table 1). An equally large amount of bounded SBR (85\%) was obtained for CR/SBR at 60/40 (by weight) vulcanizate. $\mathrm{CR} / \mathrm{SBR}$ at $40 / 60$ (by weight) vulcanizate was characterized by a noticeably lower amount of bounded SBR at $22 \%$. This indicates a selective crosslinking of $\mathrm{Cu}_{2} \mathrm{O}$. The lower amount of $\mathrm{CR}$ in the blend causes less interelastomer interactions and consequently the elution of unbound SBR by the solvent.

The values of the first elasticity constant $\left(2 C_{1}\right)$ are directly proportional to the crosslinking degree. 
Table 1 Selected properties of CR/SBR blends crosslinked with copper(I) oxide ( $4 \mathrm{phr}$ of $\left.\mathrm{Cu}_{2} \mathrm{O}\right) ; T=160{ }^{\circ} \mathrm{C}$, $t=20-30 \mathrm{~min}$

\begin{tabular}{|c|c|c|c|c|c|}
\hline \multicolumn{6}{|c|}{ Compositions of blends (phr) } \\
\hline CR & 100 & 80 & 60 & 40 & 20 \\
\hline SBR & 0 & 20 & 40 & 60 & 80 \\
\hline $\mathrm{Cu}_{2} \mathrm{O}$ & 4 & 4 & 4 & 4 & 4 \\
\hline Stearic acid & 1 & 1 & 1 & 1 & 2 \\
\hline$t_{\mathrm{v}}$ & 30 & 20 & 20 & 20 & 60 \\
\hline \multicolumn{6}{|c|}{ Equilibrium volume swelling of crosslinked samples } \\
\hline$Q_{\mathrm{V}}^{\mathrm{T}}\left(\mathrm{cm}^{3} / \mathrm{cm}^{3}\right)$ & $5.28 \pm 0.07$ & $6.85 \pm 0.14$ & $9.90 \pm 0.11$ & $11.71 \pm 0.10$ & $16.86 \pm 0.34$ \\
\hline$Q_{\mathrm{V}}^{\mathrm{H}}\left(\mathrm{cm}^{3} / \mathrm{cm}^{3}\right)$ & $0.51 \pm 0.08$ & $1.07 \pm 0.07$ & $1.89 \pm 0.09$ & $3.44 \pm 0.12$ & $4.86 \pm 0.15$ \\
\hline \multicolumn{6}{|c|}{ Bounding degree of SBR with CR } \\
\hline$X_{\mathrm{SBR}}(\%)$ & - & 95 & 85 & 22 & - \\
\hline \multicolumn{6}{|c|}{ Elasticity constants of crosslinked samples } \\
\hline $2 C_{1}\left(\mathrm{kG} / \mathrm{cm}^{2}\right)$ & $1.50 \pm 0.04$ & $1.31 \pm 0.04$ & $1.05 \pm 0.04$ & $0.58 \pm 0.05$ & $\mathrm{D}$ \\
\hline $2 C_{2}\left(\mathrm{kG} / \mathrm{cm}^{2}\right)$ & $9.58 \pm 0.31$ & $3.45 \pm 0.33$ & $2.23 \pm 0.23$ & $0.68 \pm 0.04$ & $\mathrm{D}$ \\
\hline \multicolumn{6}{|c|}{ Real extract of crosslinked samples } \\
\hline$E_{\mathrm{R}}^{\mathrm{A}}(\mathrm{mg} / \mathrm{mg})$ & $0.068 \pm 0.002$ & $0.049 \pm 0.006$ & $0.074 \pm 0.030$ & $0.070 \pm 0.021$ & $\mathrm{D}$ \\
\hline$E_{\mathrm{R}}^{\mathrm{H}}(\mathrm{mg} / \mathrm{mg})$ & $0.059 \pm 0.001$ & $0.066 \pm 0.001$ & $0.099 \pm 0.001$ & $0.137 \pm 0.003$ & $\mathrm{D}$ \\
\hline
\end{tabular}

$t_{v}$ vulcanization time; $Q_{V}^{T}, Q_{V}^{H}$ equilibrium volume swelling in toluene or heptane, respectively; $X_{S B R}$ bounding degree of SBR; $2 C_{1}$ first elasticity constant; $2 C_{2}$ second elasticity constant; $E_{R}^{A}, E_{R}^{H}$ real extract in acetone or heptane, respectively; $D$ sample dissolved
Vulcanizate containing 20 weight parts of chloroprene rubber and 80 weight parts of styrene-butadiene rubber has not been tested for elasticity constant because samples would be destroyed during the test. For the CR/ SBR at 80/20 (by weight) vulcanizate, the value of $2 C_{1}$ was $1.31 \mathrm{~kg} / \mathrm{cm}^{2}$ (Table 1). The highest value of first elasticity constant was obtained for the CR vulcanizate $\left(2 C_{1}=1.5 \mathrm{~kg} / \mathrm{cm}^{2}\right)$. The value of the second elasticity constant $\left(2 C_{2}\right)$ can be interpreted as a measure of the deviation of the created network from the ideal network. The higher the $2 C_{2}$ value, the greater the deviation. The highest value of $2 C_{2}$ was obtained for the $\mathrm{CR}$ vulcanizate $\left(2 C_{2}=9.58 \mathrm{~kg} / \mathrm{cm}^{2}\right)$. Whereas for CR/SBR at $80 / 20$ (by weight) vulcanizate, $2 C_{2}$ was equal to $3.45 \mathrm{~kg} / \mathrm{cm}^{2}$. The results of elasticity constant measurements indicate that the quantity of elastomers used affects the crosslinking degree of vulcanizates. A larger amount of chloroprene rubber in the vulcanizate results in a higher crosslinking degree, which indicates the creation of more bonds during the crosslinking.

Analysis of the results of equilibrium swelling and elasticity constant allows for drawing the same conclusions. A larger number of bonds are formed in vulcanizates, where there is a greater amount of CR in the CR/SBR blend. Such dependence may result from strong interactions between copper(I) oxide and chloroprene rubber. Whereas, $\mathrm{Cu}_{2} \mathrm{O}$ does not react with the styrene-butadiene rubber. However, the obtained results do not exclude at least partial miscibility on a macroscopic scale of the used elastomers. During the heating, bonds are formed between the rubber macromolecules in the composite, which is indicated by the resistance to solvents or to the static tension of vulcanizates.

To determine the amount of non-rubber components of the elastomers in chloroprene rubber and styrene-butadiene rubber blends, the vulcanizates were subjected to extraction in boiling acetone. It was established that the smallest amount of extracted substances occurs for cured CR/ SBR at $80 / 20$ (by weight) blends, for which $E_{\mathrm{R}}^{\mathrm{A}}$ is equal to $0.049 \mathrm{mg} / \mathrm{mg}$ (Table 1). This demonstrates the strong interactions between elastomers and additives. The extraction of vulcanizates in boiling heptane will determine the amount of rubber that has dissolved. For CR vulcanizate, the $E_{\mathrm{R}}^{\mathrm{H}}$ value was $0.059 \mathrm{mg} / \mathrm{mg}$ (Table 1). With the incorporation and increasing content of SBR in the blend, the value of real extract in heptane increases, reaching the highest value ( $E_{\mathrm{R}}^{\mathrm{H}}=0.137 \mathrm{mg} / \mathrm{mg}$ ) for the CR/SBR at 40/60 (by weight) vulcanizate. The sample of CR/SBR at 20/80 (by weight) vulcanizate has been destroyed during the test in both heptane and acetone.

It has also been established that the amount of chloroprene rubber and styrene-butadiene rubber in the blend affects the mechanical properties of the obtained vulcanizates. Tensile strength is increased with the growing amount of chloroprene rubber in blends. For CR/SBR at 20/80 (by weight) vulcanizate, the value of tensile strength $\left(\mathrm{TS}_{\mathrm{b}}\right)$ was the lowest and equal to $0.8 \mathrm{MPa}$ (Fig. 2). In the case of the CR vulcanizate, the tensile strength was 5.8 MPa. The highest value of tensile strength was achieved for the cured $\mathrm{CR} / \mathrm{SBR}$ at $80 / 20$ (by weight) blend $\left(\mathrm{TS}_{\mathrm{b}}=9.5 \mathrm{MPa}\right)$. This proves the strengthening effect of the applied elastomers and their interaction with each other. 


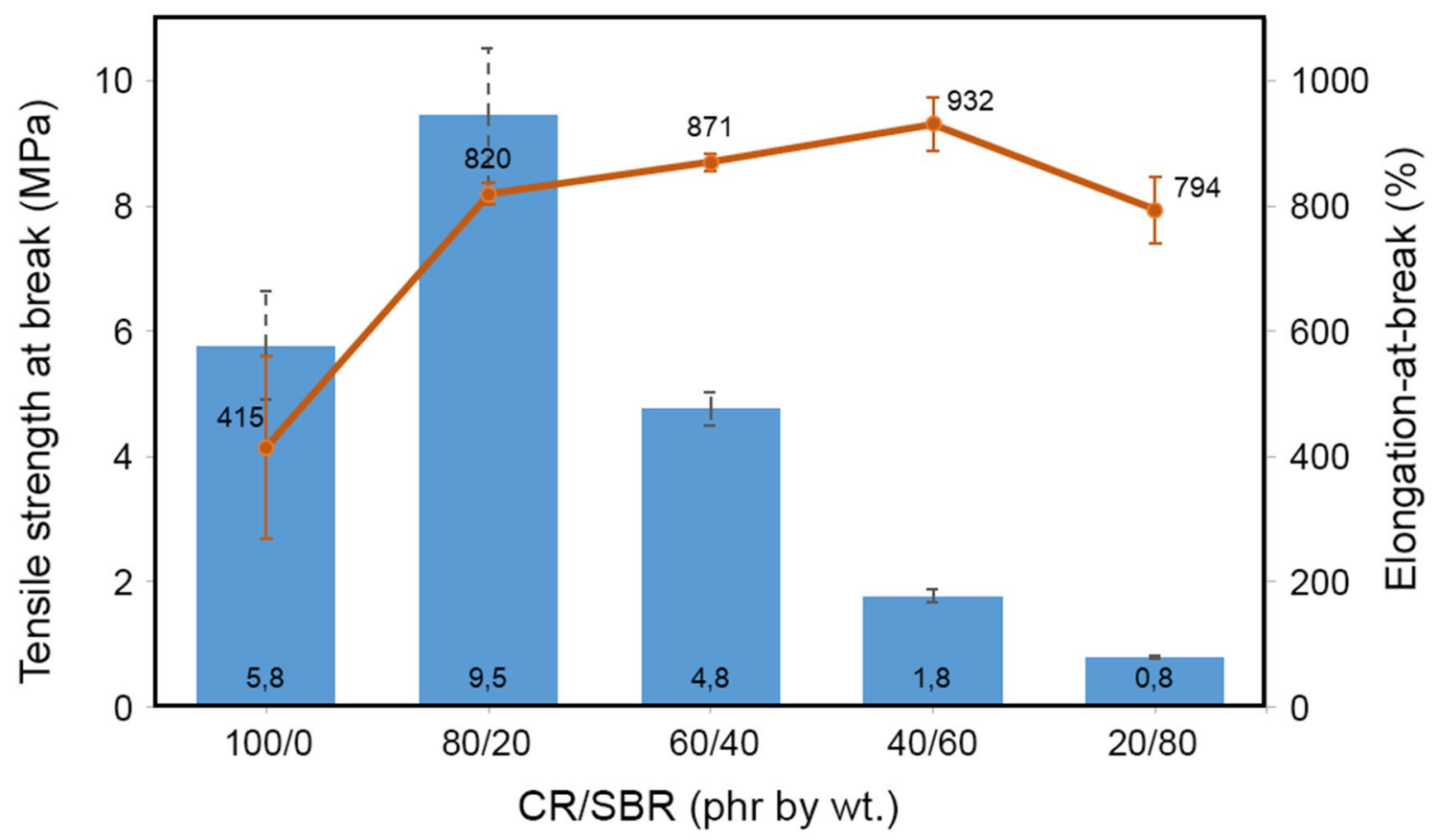

Fig. 2 Mechanical properties of CR/SBR blends crosslinked with copper(I) oxide ( 4 phr of $\mathrm{Cu} 2 \mathrm{O}$ ); $T=160{ }^{\circ} \mathrm{C}, t=20-30$ min; where: turquoise bar tensile strength-at-break, orange circled line elongation-at-break

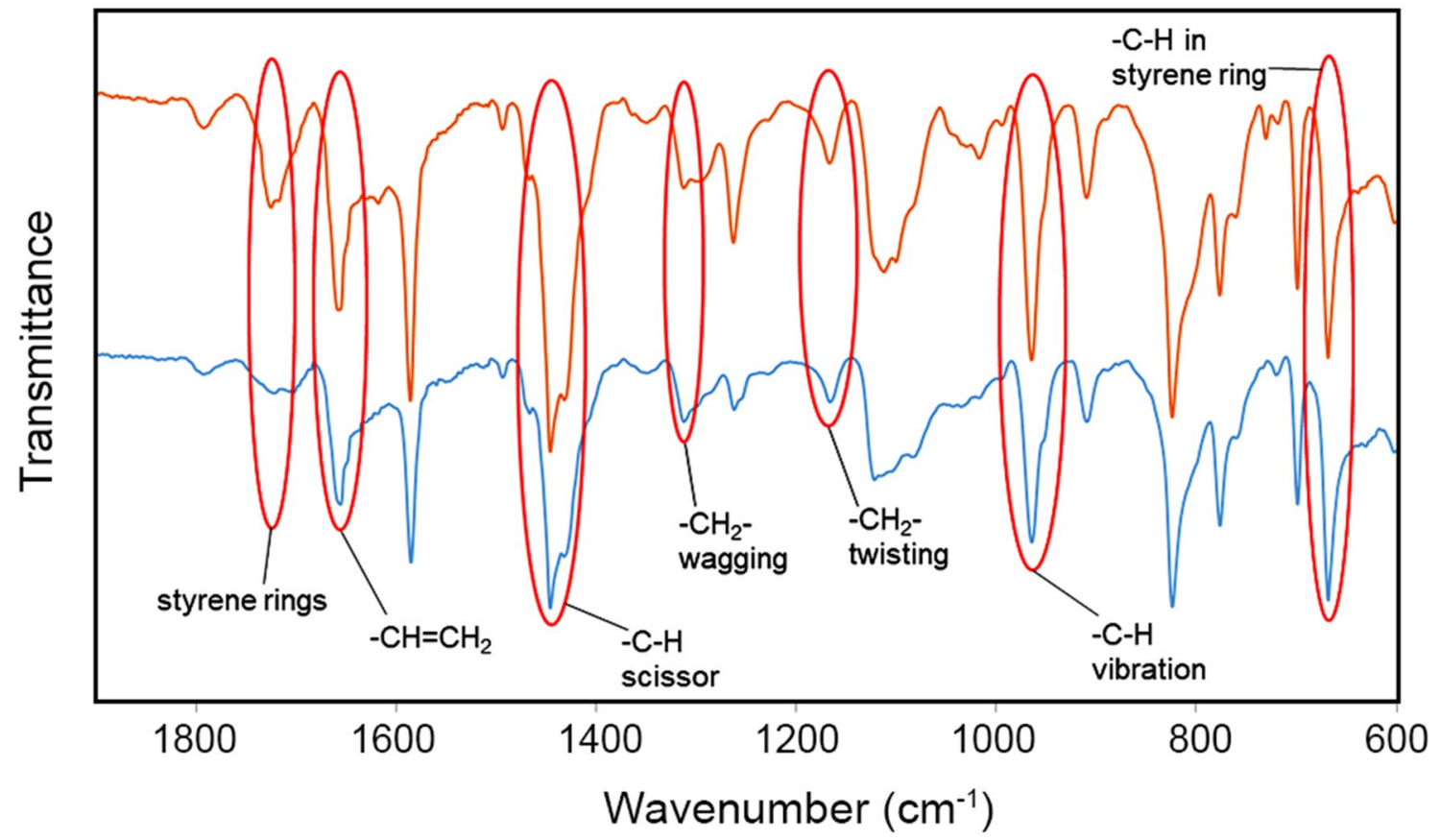

Fig. 3 IR spectra of CR/SBR ( $80 / 20$ by wt) blends crosslinked with copper(I) oxide $\left(4 \mathrm{phr}\right.$ of $\left.\mathrm{Cu}_{2} \mathrm{O}\right)$; $T=160{ }^{\circ} \mathrm{C}, t=20$ min; where: blue line before crosslinking, orange line after crosslinking

The infrared spectra confirmed that copper(I) oxide is able to crosslink the CR/SBR blends (Fig. 3). This is evidenced by changes in the intensity of characteristic absorption peaks. At the wavenumber of $700 \mathrm{~cm}^{-1}$ (out-ofplane $-\mathrm{C}-\mathrm{H}$ band in SBR aromatic ring), the intensity of the absorption peaks decreased during the heating of $\mathrm{CR} /$ 
SBR blends, which may indicate changes in the degree of substitution of the phenyl ring. Due to the heterogeneous nature of studied composites (heterogeneous blends of two rubbers and metal oxide) it is difficult to interpret them quantitatively. There was also an increase in the intensity of the peak at the wavenumber of $960 \mathrm{~cm}^{-1}$ (vibration of $-\mathrm{C}-\mathrm{H}$ in vinyl groups) during the heating of CR/SBR blends. The intensity change of the absorption peaks can also be seen at the wavenumber of $1645 \mathrm{~cm}^{-1}$, conforming to the side vinyl groups $-\mathrm{CH}=\mathrm{CH}_{2}$ in the butadiene units with 1,2 addition. The increased intensity of the absorption peaks at the wavenumber of 1180 and $1300 \mathrm{~cm}^{-1}\left(-\mathrm{CH}_{2}\right.$ twisting and wagging, respectively) may indicate the formation of bonds between macromolecular elastomers, by breaking the double bonds in the CR chain. Whereas, the increased peak intensity at a wavelength of $1470 \mathrm{~cm}^{-1}(-\mathrm{C}-\mathrm{H}$ scissor vibrations in the elastomer chains) can provide the reorganization of structures when the blends were heated in the presence of $\mathrm{Cu}_{2} \mathrm{O}$. Additionally, there were changes in the spectrum before and after the crosslinking in the range of $1670-1800 \mathrm{~cm}^{-1}$, which probably indicates oxidation of styrene rings. Lack of noticeable change in absorption bands is not synonymous with the absence of crosslinking blends. The changes in the material are significant, but they do not have a clear reference in the spectrum. Therefore, it is impossible to observe quantitative changes in the bands. IR spectra analysis allows supposing that the crosslinking of chloroprene rubber and styrene-butadiene rubber blends in the presence of copper(I) oxide takes place according to the mechanism of the Friedel-Crafts alkylation reaction [24]. Copper(I) chloride $(\mathrm{CuCl})$, which is generated in situ Lewis acid, acts as a reaction catalyst (Scheme 2). The reaction occurs between styrene rings and carbocation (CR chain with a detached chloride ion).

The proposed mechanism of crosslinking the CR/SBR blends in the presence of $\mathrm{Cu}_{2} \mathrm{O}$ is shown in reactions $\mathrm{I}-\mathrm{IV}$ (Scheme 2). Initially, dehydrohalogenation of 1,2-chloroprene meres occurs (I). Simultaneously, hydrogen chloride $(\mathrm{HCl})$ reacts with $\mathrm{Cu}_{2} \mathrm{O}$, resulting in the formation of $\mathrm{CuCl}$, which is a Lewis acid (II). Afterwards, $\mathrm{CuCl}$ acts as a catalyst for the reaction of inter-elastomer alkylation of SBR phenyl rings by $\mathrm{CR}$ chains (III and IV).

Based on the results, it was concluded that copper(I) oxide can be used as a curing agent for the chloroprene

l)

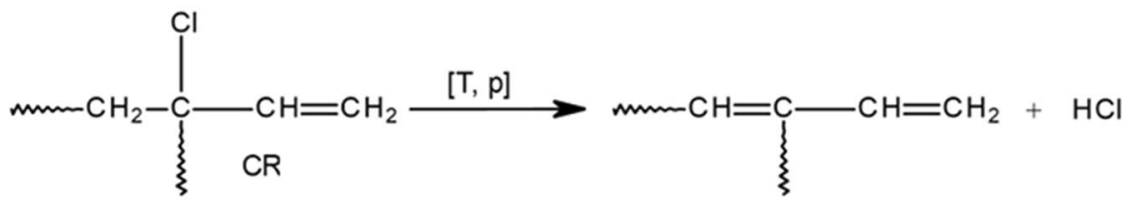

II)

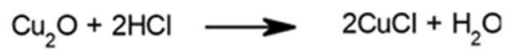

III)

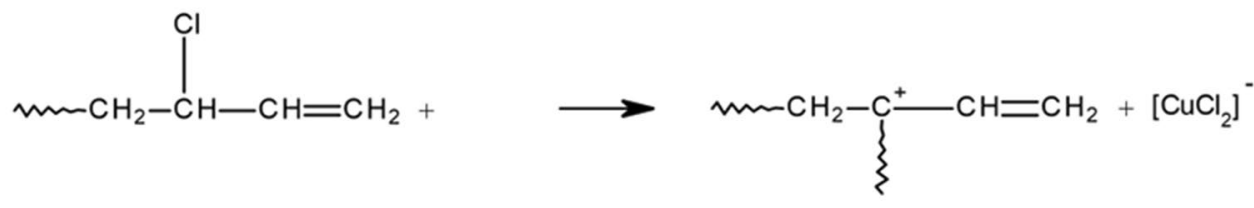

IV)

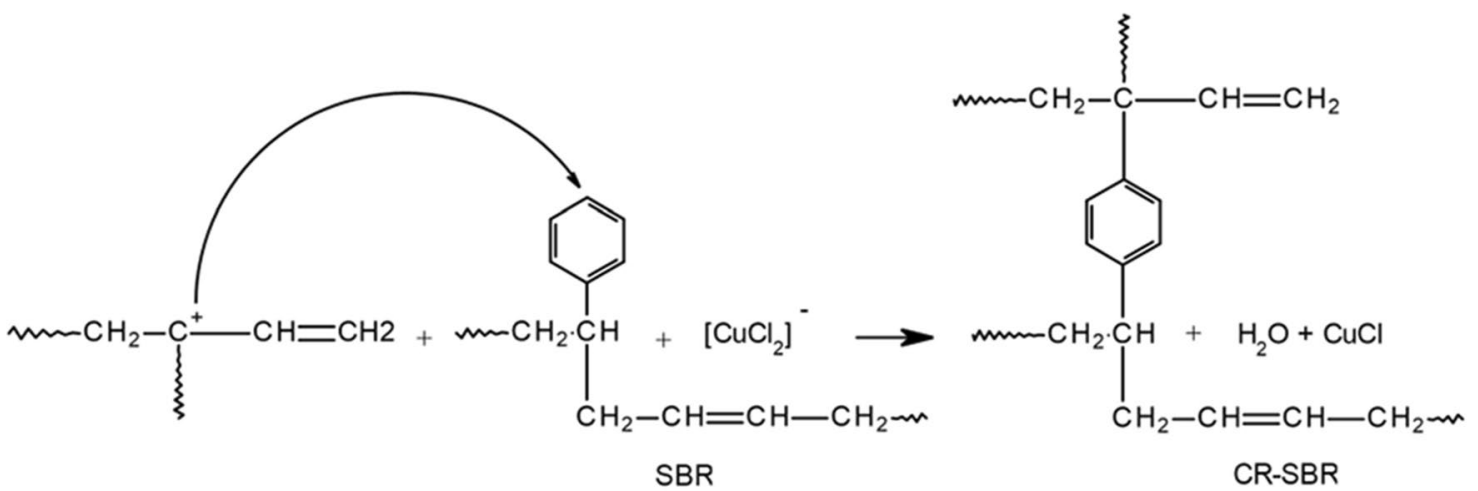

Scheme 2 Crosslinking mechanism of chloroprene rubber and styrene-butadiene rubber in the presence of copper(I) oxide 
rubber and styrene-butadiene rubber blends. However, to obtain vulcanizates with satisfactory properties, CR must be used at least in 60 weight parts. This allows obtaining vulcanizates with a good crosslinking degree and good mechanical properties. With increasing content of chloroprene rubber in the CR/SBR blend, the crosslinking degree and mechanical properties of the vulcanizates also increase, achieving the best results for the cured CR/SBR ( $80 / 20$ by weight) blend.

\section{Effect of the $\mathrm{Cu}_{2} \mathrm{O}$ amount on the crosslinking and properties of the CR/SBR blends}

Knowing copper(I) oxide ability to the crosslinking of the chloroprene and styrene-butadiene rubbers blends, it was also necessary to investigate whether the $\mathrm{Cu}_{2} \mathrm{O}$ amount affects the crosslinking of the $\mathrm{CR} / \mathrm{SBR}$ blends. For this purpose, CR/SBR ( $80 / 20$ by weight) blends containing $1,2,2.5$, 3,4 and 5 phr of $\mathrm{Cu}_{2} \mathrm{O}$ were prepared (Table 2).

The results show that the amount of copper(I) oxide affects the crosslinking degree of chloroprene and styrene-butadiene rubbers blends. The incorporation of $1 \mathrm{phr}$ of $\mathrm{Cu}_{2} \mathrm{O}$ results in a scorch time of $5.6 \mathrm{~min}$. However, the incorporation of $2 \mathrm{phr}$ and more $\mathrm{Cu}_{2} \mathrm{O}$ causes the shortening of scorch time to 2-3 min (Table 2). The shortest scorch time was obtained for a blend containing $2.5 \mathrm{phr}$ of $\mathrm{Cu}_{2} \mathrm{O}$ $\left(t_{02}=1.9 \mathrm{~min}\right)$. A blend containing $1 \mathrm{phr}$ of $\mathrm{Cu}_{2} \mathrm{O}$ was characterized by the lowest value of the minimum torque, equal to $9.1 \mathrm{dNm}$. For blends containing at least $2 \mathrm{phr}$ of $\mathrm{Cu}_{2} \mathrm{O}$ the minimum torque was about $10-11 \mathrm{dNm}$. The highest value of minimum torque was obtained for a blend containing $2 \mathrm{phr}$ of $\mathrm{Cu}_{2} \mathrm{O}$. The use of $1 \mathrm{phr}$ of $\mathrm{Cu}_{2} \mathrm{O}$ causes a slight increase in torque after $20 \mathrm{~min}$ of heating $\left(\Delta M_{20}=4.8 \mathrm{dNm}\right)$. The incorporation of at least $2 \mathrm{phr}$ of $\mathrm{Cu}_{2} \mathrm{O}$ results in a significant increase in the torque, up to a value of $\sim 28 \mathrm{dNm}$. This means that the amount of copper(I) oxide used allows the formation of noticeable interactions between the oxide and the elastomer matrix.

A similar relationship can be observed for the determination of equilibrium volume swelling in toluene and elasticity constants. For the vulcanizate containing $1 \mathrm{phr}$ of $\mathrm{Cu}_{2} \mathrm{O}$ the $Q_{\mathrm{V}}^{\mathrm{T}}$ value was $26.48 \mathrm{~cm}^{3} / \mathrm{cm}^{3}$, while

Table 2 Vulcametric parameters of CR/SBR (80/20 phr) blends crosslinked with copper(I) oxide (1-5 phr of $\left.\mathrm{Cu}_{2} \mathrm{O}\right)$ and properties of vulcanizates; $T=160^{\circ} \mathrm{C}, t=20 \mathrm{~min}$

\begin{tabular}{|c|c|c|c|c|c|c|}
\hline \multicolumn{7}{|c|}{ Compositions of blends (phr) } \\
\hline $\mathrm{CR}$ & 80 & 80 & 80 & 80 & 80 & 80 \\
\hline SBR & 20 & 20 & 20 & 20 & 20 & 20 \\
\hline Stearic acid & 1 & 1 & 1 & 1 & 1 & 1 \\
\hline $\mathrm{Cu}_{2} \mathrm{O}$ & 1 & 2 & 2.5 & 3 & 4 & 5 \\
\hline \multicolumn{7}{|c|}{ Vulcametric parameters; $T=160^{\circ} \mathrm{C}$} \\
\hline$t_{02}(\min )$ & 5.6 & 2.8 & 1.9 & 2.7 & 2.7 & 2.3 \\
\hline$t_{90}(\min )$ & 45.15 & 26.73 & 23.95 & 25.07 & 25.9 & 28.47 \\
\hline$M_{\min }(\mathrm{dNm})$ & 9.1 & 11.1 & 10.8 & 10.8 & 10.0 & 10.8 \\
\hline$\Delta M_{20}(\mathrm{dNm})$ & 4.8 & 29.5 & 22.6 & 29.6 & 29.1 & 30.9 \\
\hline \multicolumn{7}{|c|}{ Equilibrium volume swelling of crosslinked samples } \\
\hline$Q_{\mathrm{V}}^{\mathrm{T}}\left(\mathrm{cm}^{3} / \mathrm{cm}^{3}\right)$ & $26.48 \pm 1.41$ & $6.27 \pm 0.17$ & $6.60 \pm 0.07$ & $6.45 \pm 0.17$ & $6.85 \pm 0.14$ & $5.61 \pm 0.25$ \\
\hline$Q_{\mathrm{V}}^{\mathrm{H}}\left(\mathrm{cm}^{3} / \mathrm{cm}^{3}\right)$ & $1.49 \pm 0.06$ & $1.05 \pm 0.14$ & $1.08 \pm 0.06$ & $1.12 \pm 0.13$ & $1.07 \pm 0.07$ & $1.11 \pm 0.22$ \\
\hline \multicolumn{7}{|c|}{ Elasticity constants of crosslinked samples } \\
\hline $2 C_{1}\left(\mathrm{kG} / \mathrm{cm}^{2}\right)$ & $0.52 \pm 0.17$ & $1.09 \pm 0.19$ & $1.18 \pm 0.26$ & $1.23 \pm 0.17$ & $1.31 \pm 0.04$ & $1.47 \pm 0.44$ \\
\hline $2 C_{2}\left(\mathrm{kG} / \mathrm{cm}^{2}\right)$ & $9.12 \pm 0.93$ & $5.64 \pm 0.41$ & $6.97 \pm 0.50$ & $5.36 \pm 0.61$ & $3.45 \pm 0.33$ & $4.18 \pm 0.37$ \\
\hline \multicolumn{7}{|c|}{ Real extract of crosslinked samples } \\
\hline$E_{\mathrm{R}}^{\mathrm{A}}(\mathrm{mg} / \mathrm{mg})$ & $0.085 \pm 0.001$ & $0.055 \pm 0.003$ & $0.048 \pm 0.002$ & $0.051 \pm 0.013$ & $0.049 \pm 0.006$ & $0.049 \pm 0.006$ \\
\hline \multicolumn{7}{|c|}{ Bounding degree of SBR on CR } \\
\hline$X_{\mathrm{SBR}}(\%)$ & 91 & 95 & 94 & 95 & 95 & 95 \\
\hline \multicolumn{7}{|c|}{ Mechanical properties of crosslinked samples } \\
\hline$S_{\mathrm{e} 100}(\mathrm{MPa})$ & $0.47 \pm 0.02$ & $1.11 \pm 0.26$ & $0.72 \pm 0.01$ & $0.97 \pm 0.05$ & $0.77 \pm 0.03$ & $0.88 \pm 0.04$ \\
\hline$S_{\mathrm{e} 200}(\mathrm{MPa})$ & $0.54 \pm 0.03$ & $1.76 \pm 0.47$ & $0.96 \pm 0.02$ & $1.59 \pm 0.14$ & $1.12 \pm 0.07$ & $1.44 \pm 0.12$ \\
\hline$S_{\mathrm{e} 300}(\mathrm{MPa})$ & $0.61 \pm 0.03$ & $2.38 \pm 0.66$ & $1.21 \pm 0.04$ & $2.17 \pm 0.24$ & $1.53 \pm 0.15$ & $2.03 \pm 0.17$ \\
\hline $\mathrm{TS}_{\mathrm{b}}(\mathrm{MPa})$ & $2.34 \pm 0.32$ & $8.67 \pm 0.81$ & $8.40 \pm 0.13$ & $10.6 \pm 1.2$ & $9.46 \pm 1.08$ & $12.7 \pm 0.8$ \\
\hline$E_{\mathrm{b}}(\%)$ & $933 \pm 21$ & $714 \pm 60$ & $805 \pm 12$ & $838 \pm 19$ & $820 \pm 18$ & $877 \pm 16$ \\
\hline
\end{tabular}

$t_{02}$ scorch time, $t_{90}$ cure time, $M_{\min }$ minimum torque, $\Delta M_{20}$ torque increase after $20 \mathrm{~min}$ of heating, $S_{e 100}$ stress at an elongation of $100 \%, T S_{b}$ tensile strength, $E_{b}$ elongation-at-break, other symbols as in Table 1 
for blends crosslinked with at least $2 \mathrm{phr}$ of $\mathrm{Cu}_{2} \mathrm{O}$ it was about $6.4 \mathrm{~cm}^{3} / \mathrm{cm}^{3}$ (Table 2). Vulcanizate containing $5 \mathrm{phr}$ of $\mathrm{Cu}_{2} \mathrm{O}$ was characterized by the lowest value of equilibrium volume swelling in toluene $\left(Q_{\mathrm{V}}^{\mathrm{T}}=5.61 \mathrm{~cm}^{3} / \mathrm{cm}^{3}\right)$. The $Q_{\mathrm{V}}^{\mathrm{H}}$ value for vulcanizate containing $1 \mathrm{phr}$ of $\mathrm{Cu}_{2} \mathrm{O}$ was the highest and equal to $1.49 \mathrm{~cm}^{3} / \mathrm{cm}^{3}$. However, for vulcanizates containing at least $2 \mathrm{phr}$ of $\mathrm{Cu}_{2} \mathrm{O}$, the $Q_{\mathrm{V}}^{\mathrm{H}}$ value ranged from $1.05 \mathrm{~cm}^{3} / \mathrm{cm}^{3}$ (for $2 \mathrm{phr}$ of $\mathrm{CuO}$ ) to $1.12 \mathrm{~cm}^{3} / \mathrm{cm}^{3}$ (for $3 \mathrm{phr}$ of $\mathrm{CuO}$ ). The amount of bounded SBR for vulcanizates containing at least $2 \mathrm{phr}$ of $\mathrm{Cu}_{2} \mathrm{O}$ is $94-95 \%$. Only for CR/SBR $(80 / 20 \mathrm{phr})$ vulcanizate the amount of bounded SBR is $91 \%$. The lowest value of the first elasticity constant $\left(2 C_{1}=0.52 \mathrm{~kg} / \mathrm{cm}^{2}\right)$ was achieved by the blend crosslinked with $1 \mathrm{phr}$ of $\mathrm{Cu}_{2} \mathrm{O}$. For vulcanizates containing 2-4 phr of $\mathrm{Cu}_{2} \mathrm{O}$ this value was $\sim 1.2 \mathrm{~kg} / \mathrm{cm}^{2}$, while for a vulcanizate containing $5 \mathrm{phr}$ of $\mathrm{Cu}_{2} \mathrm{O}$ the first elasticity constant reached the highest value $\left(2 C_{1}=1.47 \mathrm{~kg} / \mathrm{cm}^{2}\right)$. The highest value of the second constant elasticity was obtained for vulcanizate containing $1 \mathrm{phr}$ of $\mathrm{Cu}_{2} \mathrm{O}\left(2 C_{2}=9.12 \mathrm{~kg} / \mathrm{cm}^{2}\right)$. Whereas, the smallest value, $2 C_{2}=3.45 \mathrm{~kg} / \mathrm{cm}^{2}$, was obtained for vulcanizate containing $4 \mathrm{phr}$ of $\mathrm{Cu}_{2} \mathrm{O}$. These results confirm that the use of $1 \mathrm{phr}$ of $\mathrm{Cu}_{2} \mathrm{O}$ is insufficient to obtain an advanced network. The network created during the crosslinking has a small number of bonds. This is evidenced by a slight torque increase and a very high value of equilibrium swelling volume in toluene. The use of at least $2 \mathrm{phr}$ of $\mathrm{Cu}_{2} \mathrm{O}$ causes the creation of a network with a significant number of bonds.

The amount of substances extracted from vulcanizate samples containing $1 \mathrm{phr}$ of $\mathrm{Cu}_{2} \mathrm{O}$ was $0.085 \mathrm{mg} / \mathrm{mg}$, which is the highest value (Table 2). For vulcanizates containing more than $1 \mathrm{phr}$ of $\mathrm{Cu}_{2} \mathrm{O}$ the value of the real extract oscillated around $0.05 \mathrm{mg} / \mathrm{mg}$. A smaller content of real extract means that a larger amount of copper(I) oxide has been bonded to the elastomer matrix.

It was also established that the amount of copper(I) oxide affects the properties of the produced vulcanizates. The incorporation of at least $2 \mathrm{phr}$ of $\mathrm{Cu}_{2} \mathrm{O}$ results in vulcanizates with a strength of 8-10 MPa, up to the maximum $\mathrm{TS}_{\mathrm{b}}$ value $(12.7 \mathrm{MPa})$ for vulcanizate containing $5 \mathrm{phr}$ of $\mathrm{Cu}_{2} \mathrm{O}$ (Table 2). For comparison, the chloroprene rubber conventionally crosslinked (with $4 \mathrm{phr}$ of $\mathrm{MgO}$ and $5 \mathrm{phr}$ of $\mathrm{ZnO}$ ) achieves a tensile strength-at-break of $8 \mathrm{MPa}$. However, for styrene-butadiene rubber crosslinked with $1 \mathrm{phr}$ of dicumyl peroxide, mechanical strength does not exceed $2 \mathrm{MPa}$. It is noticeable that the proposed $\mathrm{CR} / \mathrm{SBR} / \mathrm{Cu}_{2} \mathrm{O}$ compositions are characterized by better properties than the standard used CR or SBR [25, 26].

The results of the mechanical properties determinations arise directly from the indicated crosslinking degree. The small amount of bonds formed in heated CR/SBR blends in the presence of $1 \mathrm{phr}$ of copper(I) oxide results in an easily deformable network. A consequence of a slightly developed network is that the mechanical strength of the CR/SBR/ $\mathrm{Cu}_{2} \mathrm{O}(80 / 20 / 1$ by weight) vulcanizate is small.

Based on the obtained results, it was established that the heating of the $\mathrm{CR} / \mathrm{SBR}$ blend containing $1 \mathrm{phr}$ of $\mathrm{Cu}_{2} \mathrm{O}$ causes the creation of a network with a small number of bonds. Such a structure, with a slight crosslinking degree, is insufficient from the point of mechanical and functional properties. The application of $2 \mathrm{phr}$ of $\mathrm{Cu}_{2} \mathrm{O}$ or more leads to obtaining vulcanizates with good properties. An increase in the amount of copper(I) oxide above this value does not significantly improve the properties of the vulcanizates, all show similar characteristics. This may indicate that only a certain amount of the copper(I) oxide reacts with the rubbers forming the bonds. The remaining, unreacted $\mathrm{Cu}_{2} \mathrm{O}$ can fulfil the strengthening function of fillers. The most optimal is the use of $3 \mathrm{phr}$ of $\mathrm{Cu}_{2} \mathrm{O}$ as the crosslinking agent. This is because the use of 2, 2.5 or $4 \mathrm{phr}$ of $\mathrm{Cu}_{2} \mathrm{O}$ results in vulcanizates with a lower crosslinking degree and mechanical strength. Besides, it is economically advantageous to use a smaller amount of crosslinking agent if only slightly better properties are obtained for the vulcanizate containing $5 \mathrm{phr}$ of $\mathrm{Cu}_{2} \mathrm{O}$.

\section{Surface and thermal properties and the flammability of filled $\mathrm{CR} / \mathrm{SBR} / \mathrm{Cu}_{2} \mathrm{O}$ compositions}

The polymers flame resistance is one of the most important properties. Flammability often determines the use of polymers in the industry. However, most polymers belong to the group of combustible materials. This is a significant problem because the usage safety is associated with flammability, which is the basic determinant of the products' use. Several methods allow to determine the flame retardation in polymer materials. One of them is the selection of appropriate components of the composition, which are in themselves non-combustible materials. This allows for reducing the flammability of the entire composite. Therefore, the determination of flame resistance of the CR/SBR/ $\mathrm{Cu}_{2} \mathrm{O}$ (80/20/3 by weight) composition was the essence of this stage of work. However, in the industry, the elastomer compositions also contain fillers. Fillers not only increase the mechanical resistance and reduce the producing cost of compositions but also limit the burning of vulcanizates. Therefore, at this stage fillers were also incorporated into the composition, which 5 phr MMT (ZS1 nanofiller, which is montmorillonite modified by an ammonium salt-containing hydroxyl groups) as well as silica, china clay and chalk in the amount of $30 \mathrm{phr}$ each (Table 3 ).

Values of the scorch time and the minimum torque are similar for the unfilled blend and blends containing nanofiller, chalk or china clay $\left(t_{02} \sim 2.5 \mathrm{~min}\right.$ and $\left.M_{\text {min }} \sim 10 \mathrm{dNm}\right)$. 
Table 3 Vulcametric parameters of filled $\mathrm{CR} / \mathrm{SBR} / \mathrm{Cu}_{2} \mathrm{O}$ (80/20/3 phr) blends and properties of vulcanizates; $T=160{ }^{\circ} \mathrm{C}, t=20 \mathrm{~min}$

\begin{tabular}{|c|c|c|c|c|c|}
\hline \multicolumn{6}{|c|}{ Compositions of blends (phr) } \\
\hline $\mathrm{CR}$ & 80 & 80 & 80 & 80 & 80 \\
\hline SBR & 20 & 20 & 20 & 20 & 20 \\
\hline Stearic acid & 1 & 1 & 1 & 1 & 1 \\
\hline $\mathrm{Cu}_{2} \mathrm{O}$ & 3 & 3 & 3 & 3 & 3 \\
\hline MMT & - & 5 & - & - & - \\
\hline Silica & - & - & 30 & - & - \\
\hline China clay & - & - & - & 30 & - \\
\hline Chalk & - & - & - & - & 30 \\
\hline \multicolumn{6}{|c|}{ Vulcametric parameters; $T=160^{\circ} \mathrm{C}$} \\
\hline$t_{02}(\min )$ & 2.7 & 2.9 & 2.6 & 2.4 & 2.7 \\
\hline$t_{90}(\min )$ & 25.07 & 27.88 & 22.27 & 30.5 & 26.62 \\
\hline$M_{\min }(\mathrm{dNm})$ & 10.8 & 10.2 & 47.7 & 10.7 & 10.5 \\
\hline$\Delta M_{20}(\mathrm{dNm})$ & 29.6 & 42.0 & 62.0 & 36.0 & 37.7 \\
\hline \multicolumn{6}{|c|}{ Equilibrium volume swelling of crosslinked samples } \\
\hline$Q_{\mathrm{V}}^{\mathrm{T}}\left(\mathrm{cm}^{3} / \mathrm{cm}^{3}\right)$ & $6.45 \pm 0.17$ & $8.16 \pm 0.20$ & $3.62 \pm 0.05$ & $6.59 \pm 0.11$ & $7.95 \pm 0.16$ \\
\hline$Q_{\mathrm{V}}^{\mathrm{H}}\left(\mathrm{cm}^{3} / \mathrm{cm}^{3}\right)$ & $1.12 \pm 0.13$ & $1.37 \pm 0.21$ & $1.04 \pm 0.18$ & $1.72 \pm 0.24$ & $1.93 \pm 0.19$ \\
\hline \multicolumn{6}{|c|}{ Real extract of crosslinked samples } \\
\hline$E_{\mathrm{R}}^{\mathrm{A}}(\mathrm{mg} / \mathrm{mg})$ & $0.051 \pm 0.013$ & $0.084 \pm 0.007$ & $0.091 \pm 0.001$ & $0.054 \pm 0.001$ & $0.074 \pm 0.001$ \\
\hline$E_{\mathrm{R}}^{\mathrm{H}}(\mathrm{mg} / \mathrm{mg})$ & $0.066 \pm 0.001$ & $0.062 \pm 0.001$ & $0.048 \pm 0.001$ & $0.050 \pm 0.001$ & $0.054 \pm 0.003$ \\
\hline \multicolumn{6}{|c|}{ Mechanical properties of crosslinked samples } \\
\hline$S_{\mathrm{e} 100}(\mathrm{MPa})$ & $0.97 \pm 0.05$ & $0.99 \pm 0.03$ & $4.55 \pm 0.24$ & $1.44 \pm 0.10$ & $1.00 \pm 0.05$ \\
\hline$S_{\mathrm{e} 200}(\mathrm{MPa})$ & $1.59 \pm 0.14$ & $1.51 \pm 0.09$ & $7.31 \pm 0.39$ & $2.19 \pm 0.15$ & $1.36 \pm 0.12$ \\
\hline$S_{\mathrm{e} 300}(\mathrm{MPa})$ & $2.17 \pm 0.24$ & $2.03 \pm 0.13$ & $9.69 \pm 0.44$ & $2.83 \pm 0.28$ & $1.71 \pm 0.17$ \\
\hline $\mathrm{TS}_{\mathrm{b}}(\mathrm{MPa})$ & $10.6 \pm 1.2$ & $11.0 \pm 0.3$ & $14.2 \pm 0.7$ & $13.4 \pm 0.7$ & $10.2 \pm 0.3$ \\
\hline$E_{\mathrm{b}}(\%)$ & $838 \pm 19$ & $798 \pm 9$ & $496 \pm 38$ & $802 \pm 15$ & $773 \pm 10$ \\
\hline
\end{tabular}

Symbols such as in Tables 1 and 2
Torque increase after $20 \mathrm{~min}$ of heating for the unfilled blend was equal to $29.6 \mathrm{dNm}$ (Table 3). For blends containing nanofiller, chalk and china clay values of torque increase are slightly higher and are in the range of $36.0-42.0 \mathrm{dNm}$. Whereas, for the blend containing silica, the scorch time is the same as for the other compositions, while the minimum torque and the torque increase after $20 \mathrm{~min}$ of heating are much higher $\left(M_{\min }=47.7 \mathrm{dNm}\right.$ and $\left.\Delta M_{20}=62.0 \mathrm{dNm}\right)$. Also, the equilibrium volume swelling was greatest for the vulcanizate filled with silica $\left(Q_{\mathrm{V}}^{\mathrm{T}}=3.62 \mathrm{~cm}^{3} / \mathrm{cm}^{3}\right.$ and $\left.Q_{\mathrm{V}}^{\mathrm{H}}=1.04 \mathrm{~cm}^{3} / \mathrm{cm}^{3}\right)$. This indicates the highest impact of the active filler on the processing properties and crosslinking degree of CR/SBR blends. Whereas, vulcanizates filled with nanofiller, chalk or china clay are characterized by values of equilibrium volume swelling in toluene greater than for unfilled vulcanizate which are in the range of $6.59-8.16 \mathrm{~cm}^{3} /$ $\mathrm{cm}^{3}$. The values of equilibrium volume swelling in heptane for vulcanizates filled with nanofiller, chalk and china clay were all found to be in the range of $1.37-1.93 \mathrm{~cm}^{3} / \mathrm{cm}^{3}$. For comparison, for unfilled vulcanizate, $Q_{\mathrm{V}}^{\mathrm{T}}=6.45 \mathrm{~cm}^{3} / \mathrm{cm}^{3}$ and $Q_{\mathrm{V}}^{\mathrm{H}}=1.12 \mathrm{~cm}^{3} / \mathrm{cm}^{3}$.

The value of extraction in boiling acetone for the unfilled vulcanizate was the lowest $\left(E_{\mathrm{R}}^{\mathrm{A}}=0.051 \mathrm{mg} / \mathrm{mg}\right)$. The incorporation of the fillers increased the value of the real extract in acetone, from $0.054 \mathrm{mg} / \mathrm{mg}$ (for vulcanizate containing china clay) to $0.091 \mathrm{mg} / \mathrm{mg}$ (for vulcanizate filled with silica). However, in the case of extraction in boiling heptane, the highest value was obtained for unfilled vulcanizate $\left(E_{\mathrm{R}}^{\mathrm{H}}=0.066 \mathrm{mg} / \mathrm{mg}\right)$. The value of the real extract in heptane for filled vulcanizates is in the range of $0.062 \mathrm{mg} /$ $\mathrm{mg}$ (for vulcanizate containing nanofiller) to $0.048 \mathrm{mg} / \mathrm{mg}$ (for vulcanizate with silica). These results indicate that the incorporation of fillers limits the solubility of the material. With increasing interaction between the elastomer blend and the filler, the $E_{\mathrm{R}}^{\mathrm{H}}$ value decreases. Silica, as an active filler, interacts most with macromolecules in the CR/SBR vulcanizate.

For vulcanizate filled with silica, the tensile strength was the highest $\left(\mathrm{TS}_{\mathrm{b}}=14.2 \mathrm{MPa}\right)$, while the relative elongationat-the break was the smallest $\left(E_{\mathrm{b}}=496 \%\right)$. The high value of tensile strength was observed for vulcanizate containing china clay $\left(\mathrm{TS}_{\mathrm{b}}=13.4 \mathrm{MPa}\right)$. The use of chalk or nanofiller does not significantly affect the increase of the mechanical strength because the mechanical strength of vulcanizates containing these fillers is comparable to the $\mathrm{TS}_{\mathrm{b}}$ value of unfilled vulcanizates and amounts to $\sim 10.5 \mathrm{MPa}$ (Table 3). 
Relative elongation-at-the break for unfilled vulcanizate reached $838 \%$. For vulcanizates filled with nanofiller, china clay and chalk the result was lower and in the range from 773 to $802 \%$. The noticeable effect of silica on improving the properties of vulcanizates is related to the activity of this filler. The more developed silica surface area increases the interaction between the filler and the elastomer matrix.

The surface morphology of the phases of both used rubbers can be noticed (Fig. 4). However, the absence of a visible phase boundary implies that the chloroprene rubber and the styrene-butadiene rubber are partially miscible with each other. In the case of filled vulcanizates images, it is possible to observe agglomerates of fillers. This indicates that fillers are poorly dispersed in the elastomer matrix. Also, significant unevenness of the filled vulcanizates surfaces can be observed.

Using the DSC analysis, it was possible to determine the glass transition temperature of the blends (Table 4 and Fig. 5). For the sample containing nanofiller, two glass transition temperatures occur: first at $-53.91{ }^{\circ} \mathrm{C}$ and second at $-39.26^{\circ} \mathrm{C}$. The first glass transition temperature $\left(-53.91{ }^{\circ} \mathrm{C}\right)$ corresponds to styrene-butadiene rubber, while the second glass transition temperature $\left(-39.26{ }^{\circ} \mathrm{C}\right)$ corresponds to chloroprene rubber. The presence of two glass transition temperatures proves the low miscibility
Table 4 Glass transition temperature of unfilled and filled CR/SBR/ $\mathrm{Cu}_{2} \mathrm{O}(80 / 20 / 3 \mathrm{phr})$ vulcanizates; $T=160{ }^{\circ} \mathrm{C}, t=20 \mathrm{~min}$

\begin{tabular}{llllll}
\hline Filler & Unfilled & MMT & Silica & China clay & Chalk \\
\hline$T_{\mathrm{g}}\left({ }^{\circ} \mathrm{C}\right)$ & -39.05 & -53.91 & -38.70 & -39.98 & -38.57 \\
& & -39.26 & & & \\
\hline
\end{tabular}

$T_{g}$ glass transition temperature

of the composition ingredients. For the remaining samples, there is only one glass transition temperature, ranging from $-39.98^{\circ} \mathrm{C}$ (for a blend containing china clay) to $-38.57{ }^{\circ} \mathrm{C}$ (for a blend containing chalk). The presence of one glass transition temperature may result from the good miscibility of the used elastomers. However, the influence of the low content of styrene-butadiene rubber in CR/SBR ( $80 / 20$ by weight) blends is also possible. The endothermic peak at $\sim 40{ }^{\circ} \mathrm{C}$ results from the melting of crystallites in CR. Noticeably less crystallinity can be observed for the sample containing china clay and significant for the sample without any filler. The exothermic peak in the temperature range $119-176{ }^{\circ} \mathrm{C}$ corresponds to the blends crosslinking. For a sample without filler and containing china clay and silica, the maximum intensity of the vulcanization process occurs at a temperature of $\sim 130{ }^{\circ} \mathrm{C}$. This may indicate the

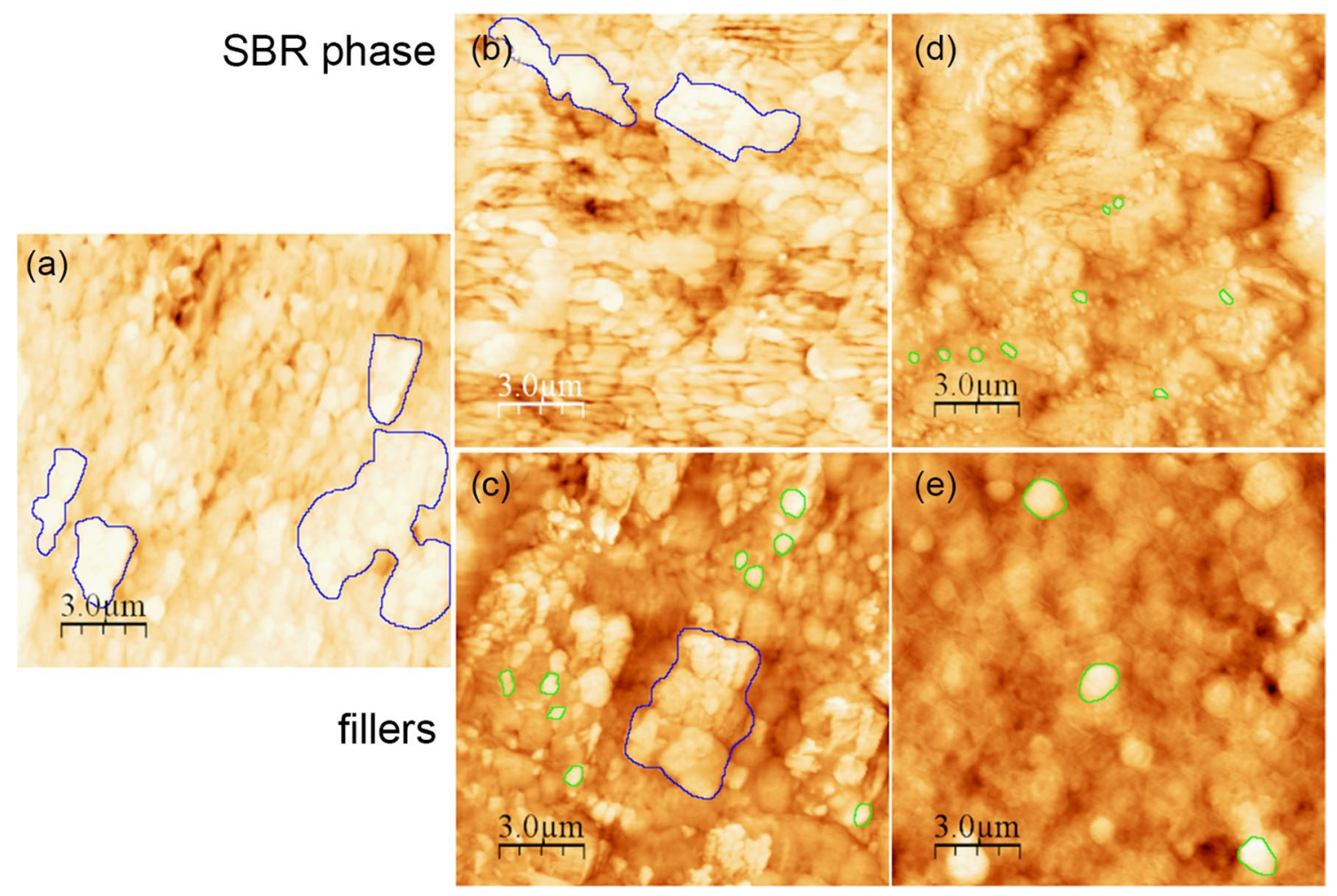

Fig. 4 AFM images of $\mathrm{CR} / \mathrm{SBR} / \mathrm{Cu}_{2} \mathrm{O}(80 / 20 / 3$ by wt) vulcanizates, unfilled (a) and filled with china clay (b), chalk (c), silica (d) and MMT (e); $T=160{ }^{\circ} \mathrm{C}, t=20 \mathrm{~min}$ 


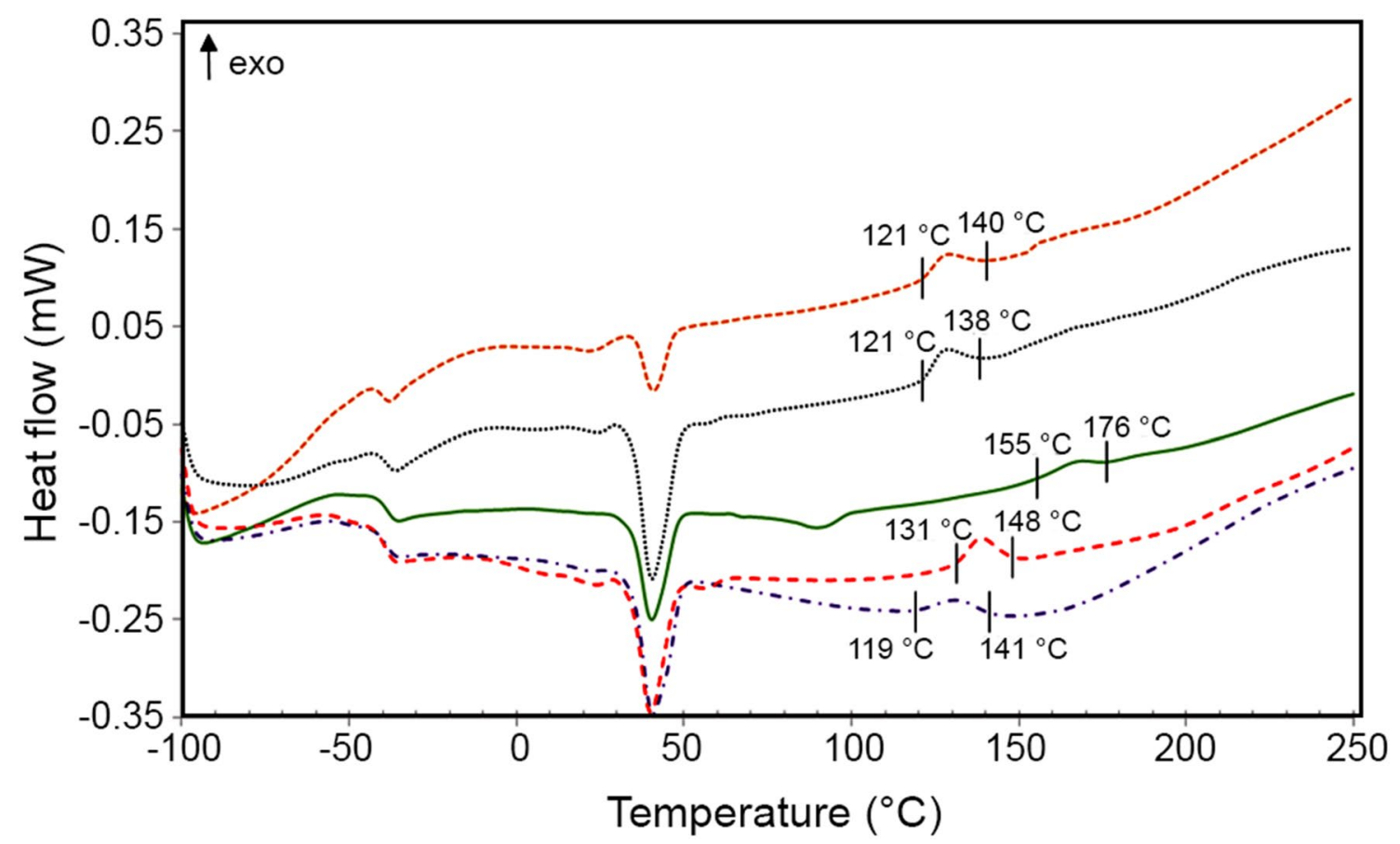

Fig. 5 DSC spectrum of unfilled and filled CR/SBR/Cu $\mathrm{Cu}_{2} \mathrm{O}(80 / 20 / 3$ by wt) vulcanizates; where: black dotted line unfilled, orange dashed line filled with china clay, green solid line filled with chalk, purple

formation of a network structure that is solidified after the material has been heated to a higher temperature. For a sample containing a nanofiller, the peak intensity appears at $138{ }^{\circ} \mathrm{C}$, which indicates vulcanization occurring. Crosslinking occurs for a CR/SBR blend containing chalk at $166^{\circ} \mathrm{C}$, which may be related to the thermal properties of the filler.

TGA analysis allowed determination of the processes occurring in vulcanizates during their heating (Fig. 6). The DTG curve, which is a derivative of the TGA curve, shows the change in the decomposition rate of vulcanizates with increasing temperature (Fig. 7). The first weight loss of samples occurs at a temperature of $\sim 370{ }^{\circ} \mathrm{C}$, where the pyrolysis of the material begins. An exception is a vulcanizate containing chalk, for which temperature peak was reached at $387^{\circ} \mathrm{C}$. For the unfilled vulcanizate, the weight loss as a result of pyrolysis is the largest and amounts 30\%. For a vulcanizate containing nanofiller, the weight loss is $25 \%$. Whereas for vulcanizates containing chalk, china clay and silica, the weight loss is $\sim 21 \%$. These values indicate the stability of the filler structure at the initial matrix decomposition. The second stage of pyrolysis occurs at a temperature range of $455-480{ }^{\circ} \mathrm{C}$. The largest weight loss $(29 \%)$ occurs for unfilled vulcanizate. For a vulcanizate containing a nanofiller, the weight loss is $26 \%$. For both of these materials, the second pyrolysis stage occurs at $\sim 455^{\circ} \mathrm{C}$. For vulcanizates containing chalk, china clay or silica, pyrolysis occurs at a temperature of $\sim 480{ }^{\circ} \mathrm{C}$, and the weight loss is in the range dash dotted line filled with silica, red dashed line filled with MMT; $T=160{ }^{\circ} \mathrm{C}, t=20 \mathrm{~min}$

from $14 \%$ (for a sample containing chalk) to $21 \%$ (for a sample containing china clay). As in the first stage of pyrolysis, the smallest weight loss is associated with the structure of fillers in the elastomer matrix. The differences between the weight loss for chalk, china clay or silica containing samples may be due to the thermal stability of these fillers. The decomposition rate of vulcanizates is comparable for both stages of pyrolysis, or slightly higher for the first stage of pyrolysis. The exception is the chalk-containing vulcanizate, for which the first stage of pyrolysis is much more intense than the second. At a temperature of $\sim 635^{\circ} \mathrm{C}$, carbon black formed during pyrolysis combust as a result of changing gas from argon to air. For china clay-containing vulcanizates, this process occurs at $698^{\circ} \mathrm{C}$.

The flammability of filled, crosslinked CR/SBR blends was also tested. CR cured conventionally with zinc oxide and magnesium oxide is a flame retardant material. Conventional CR vulcanizates are characterized by flammability and are determined by the oxygen index (OI) method. The OI value of conventional CR vulcanizates is equal to $26 \%$ [27]. In contrast, SBR is a combustible rubber. The value of the oxygen index of SBR vulcanizates is 18\% [28]. However, the compositions obtained in this work are noncombustible materials. The unfilled $\mathrm{CR} / \mathrm{SBR} / \mathrm{Cu}_{2} \mathrm{O}(80 / 20 / 3$ by weight) composition has an OI value of $33.3 \%$. This demonstrates the strong flame resistance of the resulting composition, which does not require the incorporation of flame 


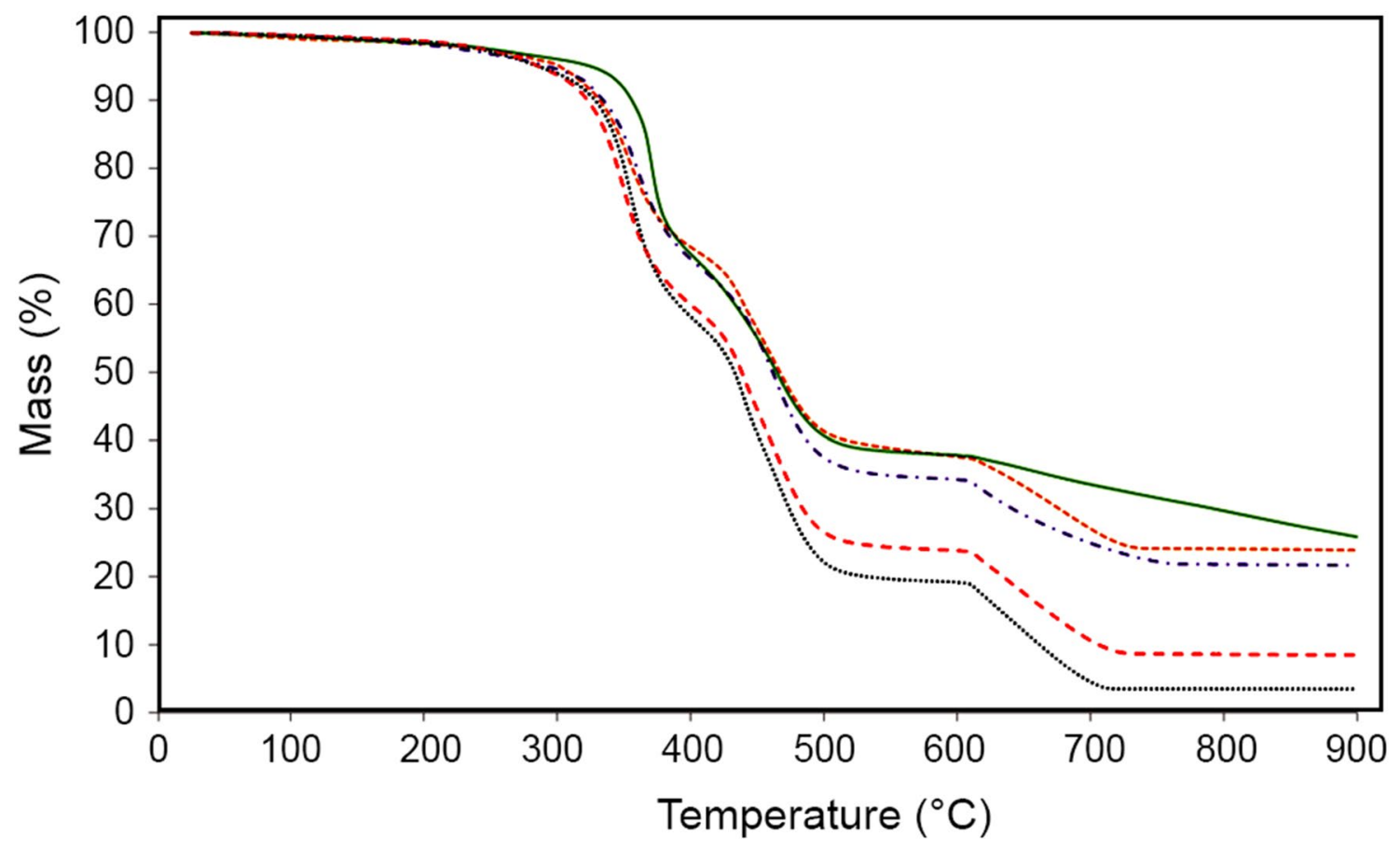

Fig. 6 TGA spectrum of unfilled and filled CR/SBR/ $\mathrm{Cu}_{2} \mathrm{O}(80 / 20 / 3$ dash dotted line filled with silica, red dashed line filled with MMT; by wt) vulcanizates; where: black dotted line unfilled, orange dashed $T=160{ }^{\circ} \mathrm{C}, t=20 \mathrm{~min}$ line filled with china clay, green solid line filled with chalk, purple

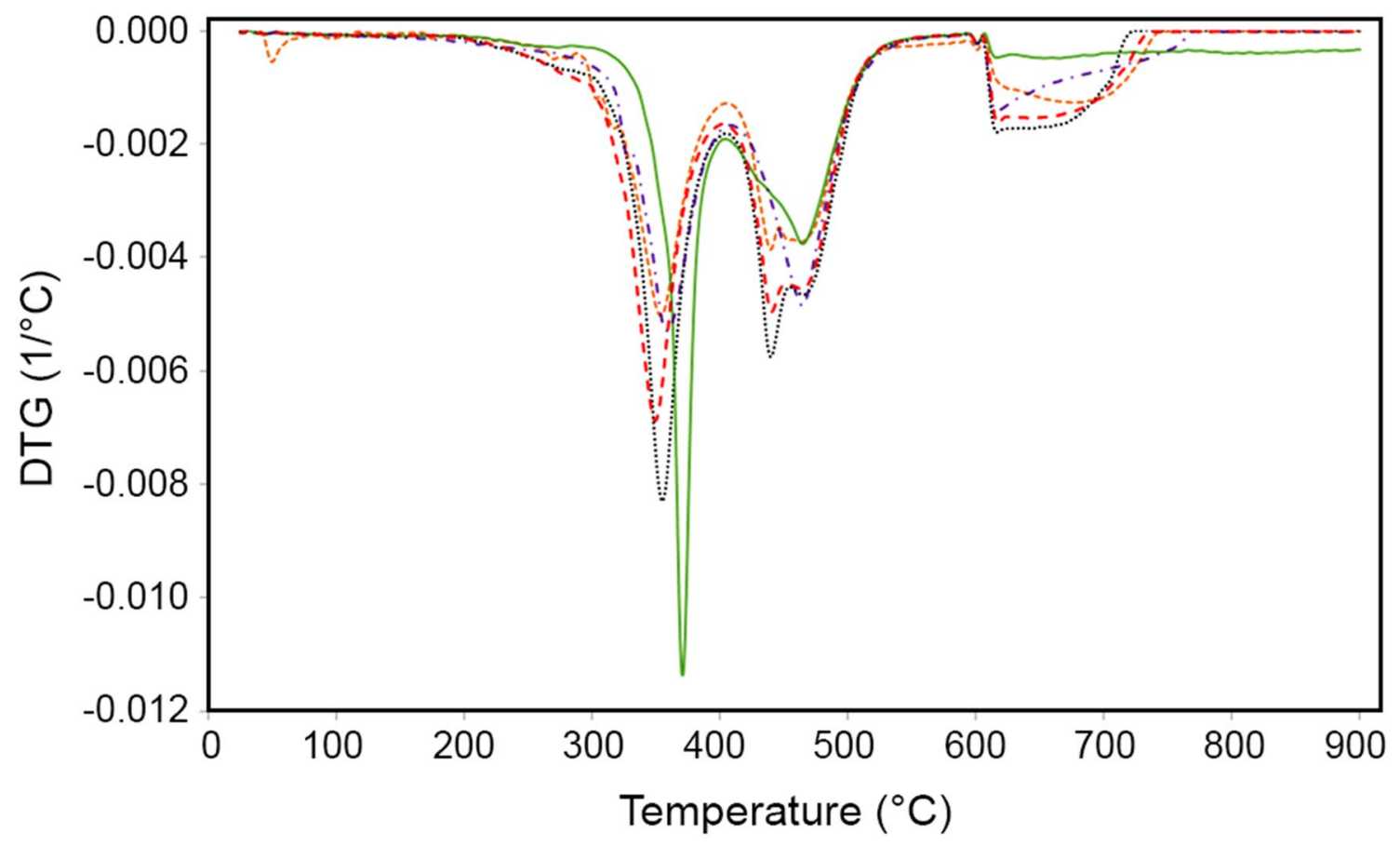

Fig. 7 DTG spectrum of unfilled and filled CR/SBR/ $\mathrm{Cu}_{2} \mathrm{O}(80 / 20 / 3$ by wt) vulcanizates; where: black dotted line unfilled, orange dashed line filled with china clay, green solid line filled with chalk, purple dash dotted line filled with silica, red dashed line filled with MMT; $T=160{ }^{\circ} \mathrm{C}, t=20 \mathrm{~min}$ 


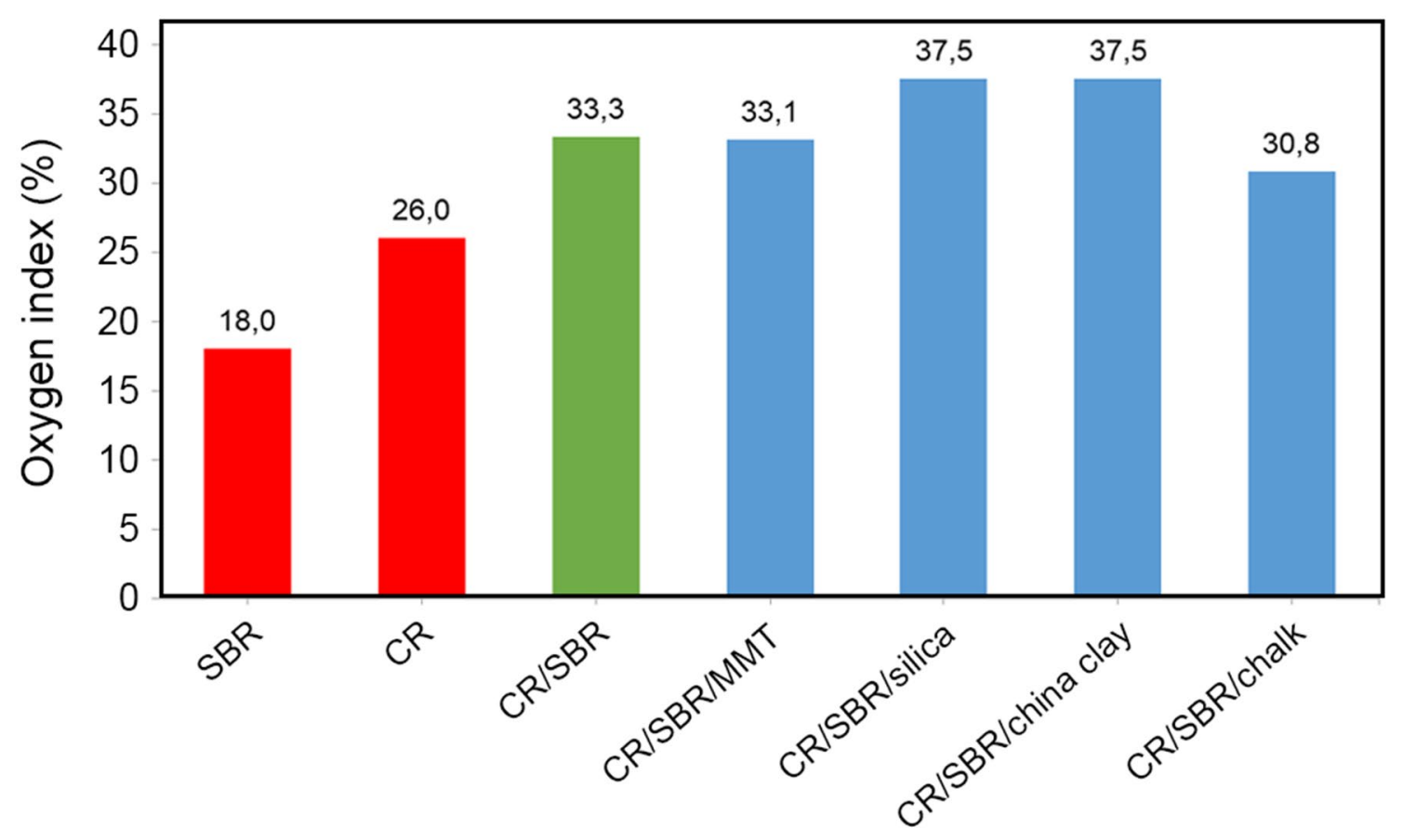

Fig. 8 Values of the oxygen index of unfilled and filled $\mathrm{CR} / \mathrm{SBR} / \mathrm{Cu}_{2} \mathrm{O}(80 / 20 / 3$ by wt $)$ vulcanizates; $T=160{ }^{\circ} \mathrm{C}, t=20 \mathrm{~min}$

retardants. The use of fillers influenced the change of the oxygen index value. The use of chalk reduces the flammability $(\mathrm{OI}=30.8 \%)$. Whereas, the use of silica or china clay influences the increase of the OI value to $37.5 \%$ (Fig. 8).

Burned samples of rubber materials behave differently, depending on the blend composition. All vulcanizates burn with a blue glow, more or less intense, which is the result of using copper(I) oxide. Also, the flame takes on a greenish color, which is related to the burning of chlorine. The cured CR/SBR blends containing silica were burned with a flame, which covered the sample in layers. In addition, the sparking occurred during the combustion. After the measurement, the sample containing silica did not retain its shape, delaminated, was brittle and quickly decayed into ashes. The incorporation of china clay caused the sample to retain its shape after the burning and the surface was covered by an ash layer. Samples of vulcanizates containing chalk retained their shape after the test and the surface was covered with a black coating. Whereas, samples containing nanofiller burned with a smoky flame. After the test, the sample skeleton remained with jagged edges.

\section{Conclusion}

In this paper, it was shown that copper(I) oxide can be used as an unconventional curing agent for new chloroprene rubber and styrene-butadiene rubber blends (CR/SBR). The amount of rubbers in the blends affects the properties of the vulcanizates. SBR does not crosslink under the influence of $\mathrm{Cu}_{2} \mathrm{O}$. The crosslinking degree of vulcanizates and their strength properties improve with the increasing CR content in CR/SBR blends. The proportion of used rubbers affects the properties of the vulcanizates. The CR/SBR ( $80 / 20$ by weight) vulcanizate is characterized by the best properties. Also, the amount of copper(I) oxide affects the crosslinking course of the CR/SBR blends and the properties of vulcanizates. To obtain a vulcanizate with satisfactory properties it is necessary to use at least $2 \mathrm{phr}$ of $\mathrm{Cu}_{2} \mathrm{O}$ for the crosslinking of the CR/SBR blends. Application of 2-5 phr of copper(I) oxide leads to the crosslinking of the CR/SBR blends with good and comparable properties. The obtained CR/SBR/ $\mathrm{Cu}_{2} \mathrm{O}(80 / 20 / 3$ by weight) composite is the material with the most optimal crosslinking degree and mechanical strength, among the other compositions. The incorporation of fillers, in particularly silica, affects the change of the crosslinking degree and mechanical properties. The thermal analysis allowed to determine the changes occurring in the materials during their heating. All CR/SBR blends, except one containing nanofiller, were characterized by one glass transition temperature. This may indicate at least partial miscibility of both used elastomers. The low intensity of the peaks corresponding to the crosslinking of the CR/SBR ( $80 / 20$ by weight) blends may indicate a small amount of bonds formed during heating. Another possibility is the formation of connections between chains with a low binding energy. The decomposition rate of vulcanizates is comparable for both stages of pyrolysis, or slightly higher for the first stage of 
pyrolysis. The exception is the chalk-containing vulcanizate, for which the first stage of pyrolysis is much more intense. The use of chalk, china clay or silica increases the thermal stability of the vulcanizates. Presence in the composition of flame retardants is not required. Besides, the use of silica or chalk as a filler further improves the resistance to flames. The obtained materials may have potential applications in industry, including the production of cables and other products that may be in contact with fire. The presented test results are the basis for Polish patent no. 231634 [29].

Author contributions All authors contributed to the study conception and design. Material preparation, data collection and analysis were performed by PK, AS-K, AO and KS. The first draft of the manuscript was written by $\mathrm{PK}$ and all authors commented on previous versions of the manuscript. All authors read and approved the final manuscript.

\section{Compliance with ethical standards}

Conflict of interest The authors declare that they have no conflict of interest.

Ethical standards This article does not contain any studies with human participants or animals performed by any of the authors.

Open Access This article is licensed under a Creative Commons Attribution 4.0 International License, which permits use, sharing, adaptation, distribution and reproduction in any medium or format, as long as you give appropriate credit to the original author(s) and the source, provide a link to the Creative Commons licence, and indicate if changes were made. The images or other third party material in this article are included in the article's Creative Commons licence, unless indicated otherwise in a credit line to the material. If material is not included in the article's Creative Commons licence and your intended use is not permitted by statutory regulation or exceeds the permitted use, you will need to obtain permission directly from the copyright holder. To view a copy of this licence, visit http://creativecommons.org/licenses/by/4.0/.

\section{References}

1. Li J, Isayev AI, Ren X, Soucek MD (2016) Effect of norbornyl modified soybean oil on CB-filled chloroprene rubber. J Appl Polym Sci 133:43809

2. Zhang P, Huang G, Qu L, Nie Y, Weng G, Wu J (2011) Straininduced crystallization behavior of polychloroprene rubber. J Appl Polym Sci 121:37-42

3. Bĕhal M, Duchăček V (1988) Thermovulcanization of polychloroprene rubber and its blends with poly(vinyl chloride). J Appl Polym Sci 35:507-515

4. De SK, White JR (2001) Rubber technologist's handbook. Rapra Technology Limited, Shropshire

5. Maya MG, Soney GC, Thomasukutty J, Lekshmi K, Sabu T (2018) Development of a flexible and conductive elastomeric composite based on chloroprene rubber. Polym Test 65:256-263

6. Tchalla ST, Le Gac PY, Maurin R, Créac'hcadec R (2017) Polychloroprene behaviour in a marine environment: role of silica fillers. Polym Degrad Stab 139:28-37

7. Ishigaki Y, Mori H (2017) RAFT-mediated emulsion polymerization of chloroprene and impact of chain-end structure on chloroprene rubbers. J Appl Polym Sci 135:46008
8. Kapgate BP, Das C, Das A, Basu D, Wiessner S, Reuter U, Heinrich G (2016) Reinforced chloroprene rubber by in situ generated silica particles: evidence of bound rubber on the silica surface. J Appl Polym Sci 133:43717

9. Thomas SP, Mathew EJ, Marykutty CV (2012) Synthesis and effect of surface modified nano $\mathrm{ZnO}$ in natural rubber vulcanization. J Appl Polym Sci 124:3099-3107

10. Corish PJ (1994) In: Eirich FR, Erman B, Mark JE (eds) Science and technology of rubber. Elsevier Inc., San Diego

11. Ongwongsakul K, Rempel GL, Poompradub S, Hinchiranan N (2016) Comparative behavior of in situ silica generation in saturated rubbers: EPDM and hydrogenated natural rubber. J Appl Polym Sci 134:44748

12. Sathi SG, Jang JY, Jeong KU, Nah C (2016) Thermally stable bromobutyl rubber with a high crosslinking density based on a 4,4'-bismaleimidodiphenylmethane curing agent. J Appl Polym Sci 133:44092

13. Ding Z, Li Y, He M, Wang W, Wang C (2017) The combination of expandable graphite, organic montmorillonite, and magnesium hydrate as fire-retardant additives for ethylene-propylene-diene monomer/chloroprene rubber foams. J Appl Polym Sci 134:44929

14. Janowska G, Kucharska-Jastrzabek A, Kasiczak A, Rzymski WM (2011) Thermal properties and combustibility of cross-linked XNBR/CSM blends. Part I. Influence of the magnesium oxide. J Therm Anal Calorim 104:1107-1115

15. Boonsong K, Seadan M, Lopattananon N (2008) Compatibilization of natural rubber (NR) and chlorosulfonated polyethylene (CSM) blends with zinc salts of sulfonated natural rubber. Songklanakarin J Sci Technol 30:491-499

16. Dmowska-Jasek P, Rzymski WM, Koścista E, Bociong K (2015) A new method of styrene-butadiene rubber curing using in situ generated Lewis acids. Polimery 60:742-746

17. Rzymski MW, Bociong K, Gietka K (2011) Method of modification and crosslinking of styrene-butadiene rubbers. Polish Patent No. PL 208191

18. Smejda-Krzewicka A, Olejnik A, Strzelec K (2019) The role of iron(III) oxide in chloroprene and butadiene rubber blends' crosslinking, structure, thermal and mechanical characteristics. Iran Polym J 28:313-323

19. Smejda-Krzewicka A, Olejnik A, Strzelec K (2019) The effect of metal oxide on the cure, morphology, thermal and mechanical characteristics of chloroprene and butadiene rubber blends. Polym Bull 20:1-6

20. Olejnik A, Smejda-Krzewicka A, Strzelec K, Szynkowska MI (2019) Curing and properties of chloroprene and butadiene rubber (CR/BR) blends cross-linked with copper(I) oxide or copper(II) oxide. Int J Polym Anal Charact 24:18-31

21. Olejnik A, Smejda-Krzewicka A, Strzelec K (2019) Effect of antioxidants on aging of the chloroprene rubber/butadiene rubber (CR/BR) blends. Int J Polym Anal Charact 24:475-486

22. Horcas I, Fernandez R, Gomez-Rodriguez JM, Colchero J, Gomez-Herrero J, Baro AM (2007) WSXM: a software for scanning probe microscopy and a tool for nanotechnology. Rev Sci Instrum 78:013705

23. Ślusarski L, Janowska G, Szkodziński A, Niedomagała M, Harwaziński A (1987) System for measuring the oxygen index of plastics, natural materials or rubber. Polish Patent No. PL 129411

24. March J, Smith MB (2007) March's advanced organic chemistry. Wiley, New Jersey

25. Chokanandsombat $\mathrm{Y}$, Sirisinha $\mathrm{C}$ (2013) $\mathrm{MgO}$ and $\mathrm{ZnO}$ as reinforcing fillers in cured polychloroprene rubber. J Appl Polym Sci 128:2533-2540

26. Sadhu S, Bhowmick AK (2004) Preparation and properties of nanocomposites based on acrylonitrile-butadiene rubber, styrene-butadiene rubber, and polybutadiene rubber. J Polym Sci B 42:1573-1585 
27. Smejda-Krzewicka A, Rzymski WM, Kowalski D (2015) Tin oxide cross-linking of chloroprene rubber. Polimery 60:186-191

28. Yin D, Zhang Y, Zhang Y, Peng Z (2001) Effect of methacrylic acid on the mechanical properties of peroxide-cured SBR vulcanizates filled with $\mathrm{Al}(\mathrm{OH})_{3}$. Polym Polym Compos 9:523-529
29. Smejda-Krzewicka A, Kobędza P, Olejnik A, Strzelec K (2019) Method for obtaining elastomere compositions that contain styrene-butadiene rubber with increased burning resistance. Polish Patent No. PL 231634 